\title{
Validation of High-Resolution Gridded Rainfall Datasets for Climate Applications in the Philippines
}

\author{
J. C. Albert C. Peralta and Gemma Teresa T. Narisma \\ Atmospheric Science Program, Department of Physics, School of Science and Engineering, Ateneo de Manila University, \\ and Regional Climate Systems Laboratory, Manila Observatory, Quezon City, Philippines \\ FAYE ABigail T. CRUZ \\ Regional Climate Systems Laboratory, Manila Observatory, Quezon City, Philippines
}

(Manuscript received 19 November 2019, in final form 9 April 2020)

\begin{abstract}
Gridded rainfall products could augment the shortage of available rainfall data in archipelagic countries like the Philippines, where weather stations are still sparsely distributed especially over its remote and lessdeveloped islands. However, these products need to be validated first using ground measurements to determine their ability to represent properties of local rainfall. This study compares four high-resolution, gridded datasets-APHRODITEv1101, CHIRPSv2, TRMM 3B42v7, and PERSIANN-CDR-with respect to 49 synoptic weather stations over the Philippines from 1998 to 2005. The performance of these datasets was assessed in terms of bias, distribution, and different statistical error metrics and skill scores across time scales and climate types. Results show that all the datasets were able to capture the basic climatology and to varying extents, spatial patterns of Philippine rainfall. TRMM 3B42v7 has the least overall average monthly bias and most closely resembles the rainfall distribution observed at weather stations, especially dry days and torrential rain days for the whole Philippines. APHRODITEv1101 performs best in terms of error metrics and skill scores but displays consistent underestimates. CHIRPSv2, on the other hand, best captures the seasonal rainfall peaks in the different climate types in the Philippines but is prone to larger errors. Last, PERSIANN-CDR shows generally poor metrics and rainfall distributions, in comparison to the other datasets. These key findings are used to identify possible research applications in the Philippines that are best suited for each dataset.
\end{abstract}

\section{Introduction}

Rainfall plays a major influence on climate variability in the Philippines. At seasonal scales, rainfall is driven by the large-scale flow of the Asian summer monsoon (e.g., Murakami and Matsumoto 1994), and the Asian winter monsoon (e.g., Juneng and Tangang 2010). Tropical cyclones and low pressure systems originating from the Pacific Ocean also bring extreme rainfall to the country (Cinco et al. 2016; Bagtasa 2017). Furthermore, other well-studied global-scale phenomena such as the El Niño-Southern Oscillation (ENSO) (Hilario et al.

\footnotetext{
Supplemental information related to this paper is available at the Journals Online website: https://doi.org/10.1175/JHM-D-190276.s1.
}

Corresponding author: J. C. Albert C. Peralta, jc.peralta@obf. ateneo.edu
2009) and the Madden-Julian oscillation (MJO) (Pullen et al. 2015) are also known to modify the annual rainfall amount and distribution in the country.

There are four climate types in the Philippines, as defined by the Modified Coronas Climate Classification (Coronas 1920; Flores and Balagot 1969; Kintanar 1984). These climate types are determined based on rainfall variation observed from ground stations over the whole country, and are characterized as follows:

1) Type 1: These areas are located over the western side of the country facing the West Philippine Sea, and have two pronounced seasons: wet (typically above $100 \mathrm{~mm} \mathrm{month}^{-1}$ ) associated with the Asian summer monsoon from May to September, and dry (typically below $100 \mathrm{~mm} \mathrm{month}^{-1}$ ) from November to April.

2) Type 2: Situated over the eastern side of the country facing the Philippine Sea and the Pacific Ocean, these areas characteristically do not have a dry season but display a pronounced rainfall peak observed from 


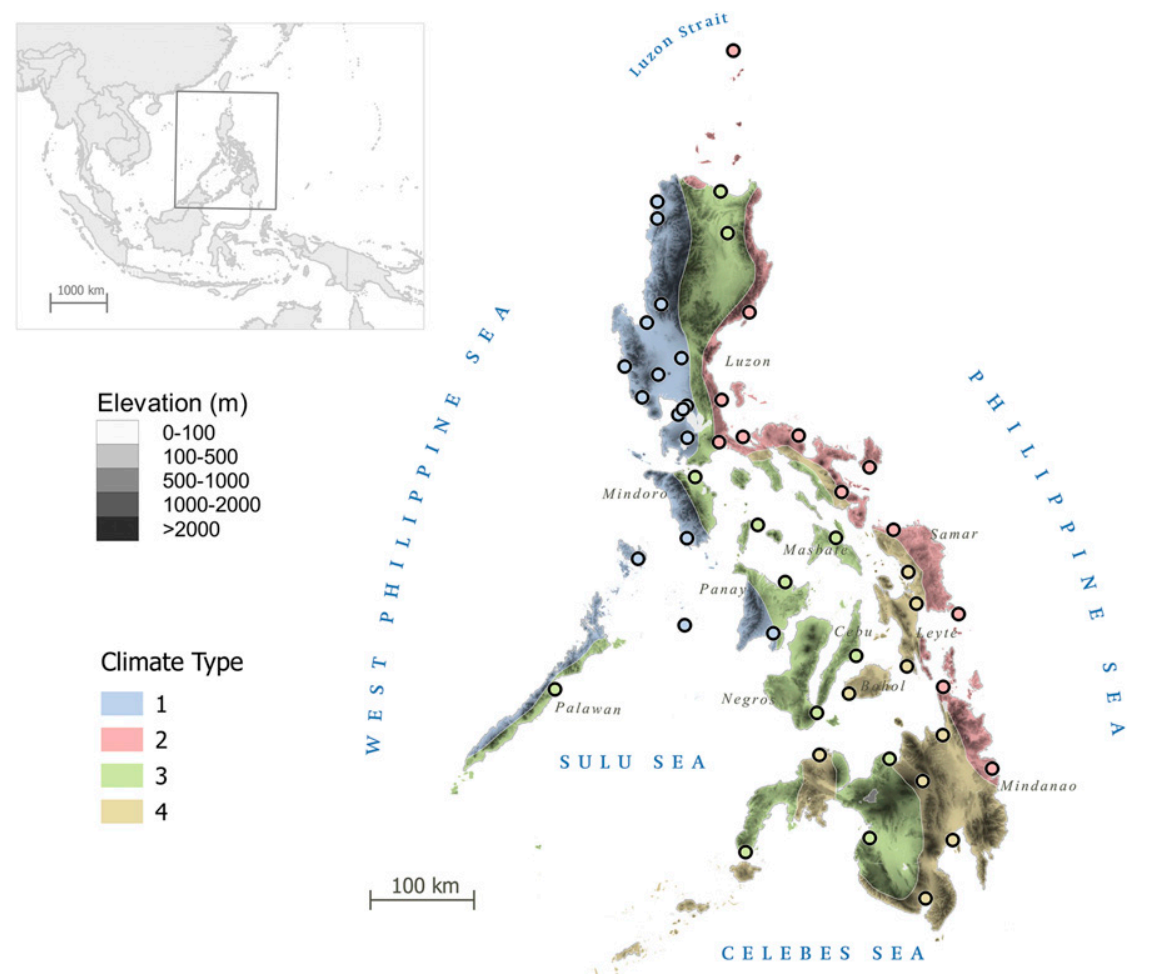

FIG. 1. Map of the climate types of the Philippines and location of the 49 PAGASA stations used. Elevation is indicated as shading. This map does not show the full extent of the maritime borders of the country.

October to January. This peak is associated with the Asian winter monsoon and western Pacific tropical cyclones.

3) Type 3: Located immediately east of Type 1, this type is either over inland areas or islands within the archipelagic seas. These areas have no pronounced peaks and have less total annual rainfall than either Type 1 or Type 2, but they record similar but slightly wetter dry months compared to Type 1 .

4) Type 4: These areas lie west of Type 2 with annual rainfall comparable to Type 3 but more or less evenly distributed over all the months. However, the profile resembles that of Type 2 because of a similar absence of a pronounced dry season.

This classification is a good survey of Philippine rainfall variability as the majority of the features described were also present when an objective clustering method was applied to rainfall data from recent station and satellite-based observations (Corporal-Lodangco and Leslie 2017). It is also proven to be useful in characterizing long-term rainfall trends and extremes indices (Cruz et al. 2013; Villafuerte et al. 2014). The spatial extent of each climate type is presented in Fig. 1.
Given the country's high vulnerability to the effects of climate change (Kreft et al. 2014), there is a pressing public need for timely and accurate rainfall data for monitoring and research. High-resolution gridded rainfall data products derived from satellite imagery and interpolated rainfall station networks are becoming increasingly available in recent years. Because of their high spatial and temporal resolution and coverage, these gridded datasets show promise as reliable and cost-effective sources of rainfall information, particularly in inaccessible rural regions where in situ measurements are either lacking or absent. The broad spatial coverage of these gridded rainfall datasets is also critical in evaluating climate models, an essential first step to account for uncertainties relevant to end-users and to provide insight into future model developments. However, these gridded rainfall datasets need to be validated first with observed station data to determine their capability to capture different rainfall characteristics that are crucial for specific applications.

Jamandre and Narisma (2013) earlier validated a selection of three gridded rainfall datasets in the Philippines, namely, the Asian Precipitation-Highly Resolved Observational Data Integration Towards Evaluation of Water Resources (APHRODITE) version 1101(Yatagai et al. 2012), Tropical Rainfall Measuring Mission (TRMM) 
3B42 version 6 (Huffman et al. 2007), and the Climate Prediction Center morphing method (CMORPH) (Joyce et al. 2004). These datasets were compared with rainfall data from eight synoptic weather stations of the national weather agency, Philippine Atmospheric, Geophysical and Astronomical Services Administration (PAGASA), from 2003 to 2005 . Their results showed that the correlation with station data of the ground-station interpolated APHRODITE is consistently better than the satellite-derived TRMM and CMORPH for all locations considered, especially the northern and eastern regions of the Philippines. They have also noted that APHRODITE and CMORPH recorded high errors for low rainfall and that TRMM gave more accurate estimates for higher rainfall values.

This paper extends the rainfall validation of Jamandre and Narisma (2013) by increasing the number of synoptic weather stations, lengthening the time period, and considering other high-resolution rainfall datasets. Section 2 of this paper describes the geographical features of the Philippines, followed by details about the datasets and methods used. The results of the different validation procedures are discussed in section 3. Finally, section 4 presents a summary of key findings and climate applications recommended per dataset.

\section{Data and methods}

\section{a. Study domain}

The Philippines is an archipelagic country located in the northeastern part of Southeast Asia (Fig. 1). It is bounded by the Luzon Strait to the north, the Philippine Sea and Pacific Ocean to the east, the West Philippine Sea (South China Sea) to the west, and the Celebes Sea to the south. The country is composed of over 7000 islands divided into three major groups: Luzon (composed of Luzon Island, Mindoro, Palawan, and neighboring small islands), Visayas (composed of major islands around the center of the archipelago), and Mindanao (composed of Mindanao Island and neighboring small islands) (Central Intelligence Agency 2019). The topography within these islands is quite complex-narrow mountain ranges, lowlands, and jagged coastlines-which also influences local-scale rainfall.

\section{b. Ground station data}

Daily rainfall data from synoptic stations of PAGASA were used as the basis for validation (Villafuerte et al. 2014; Cinco et al. 2014). Given the varying temporal coverage across the different stations, the longest common time period of station data with all four gridded datasets was used in this study, which is from 1998 to 2005. After discarding stations with more than $20 \%$ missing or invalid daily values, only 49 out of 52 available stations were included in the analysis (Table S1 in the online supplemental material). These stations are distributed across the archipelago, covering all climate types: Type 1 (16 stations), Type 2 (12 stations), Type 3 (12 stations), and Type 4 (9 stations) (Fig. 1).

\section{c. High-resolution gridded rainfall datasets}

Four gridded rainfall products were selected for validation due to their high resolution and documented performance in other tropical regions (Usman et al. 2018; Dinku et al. 2018; Diem et al. 2014; Prasetia et al. 2013). These are APHRODITE version 1101 (APHRODITEv1101) (Yatagai et al. 2012), the Climate Hazards Group Infrared Precipitation with Stations version 2 (CHIRPSv2) (Funk et al. 2015a), the Precipitation Estimation from Remotely Sensed Information using Artificial Neural Networks-Climate Data Record (PERSIANN-CDR) (Ashouri et al. 2015), and the TRMM 3B42 version 7 (TRMM 3B42v7) (Huffman et al. 2007).

APHRODITEv1101 was produced by interpolating rainfall measured by a large network of stations from national hydrological and meteorological services institutions all over the Asian continent, in addition to rainfall data provided by the World Meteorological Organization (WMO) Global Telecommunication System (GTS) (Yatagai et al. 2012). The data are available for the domains of Monsoon Asia $\left(60^{\circ}-150^{\circ} \mathrm{E}, 15^{\circ} \mathrm{S}-55^{\circ} \mathrm{N}\right)$, Middle East $\left(15^{\circ}-65^{\circ} \mathrm{E}, 25^{\circ}-45^{\circ} \mathrm{N}\right)$, and Russia $\left(15^{\circ} \mathrm{E}-165^{\circ} \mathrm{W}\right.$, $34^{\circ}-84^{\circ} \mathrm{N}$ ), covering 57 years from 1950 to 2007 . The interpolation algorithm involves a multistep interpolation process using the daily station observation weighted by its ratio to monthly and daily climatologies at a $0.05^{\circ}$ resolution grid and finally regridding to $0.25^{\circ}$ and $0.5^{\circ}$ resolution products.

CHIRPSv2 is a rainfall gridded dataset covering 1981 to the present, available at $0.05^{\circ}$ and $0.25^{\circ}$ resolution based on infrared cold cloud duration (CCD) satellite observations and station-based data. The satellite-only product, CHIRP, takes in data from two infrared imagery sources: the Globally Gridded Satellite (GridSat) archive (1981-2008) produced by NOAA's National Climate Data Center and the NOAA Climate Prediction Center (CPC TIR) dataset (2000-present). The rainfall estimates are produced by using a fixed CCD threshold and calibrated by $0.25^{\circ}$ resolution TRMM $3 \mathrm{~B} 42$ pentadal precipitation (2000-13). This is blended with station-based monthly rainfall climatology of the CHPClim dataset (Funk et al. 2015b) using a modified inverse distance weighting algorithm described in Funk et al. (2015a).

The PERSIANN-CDR dataset contains daily rainfall estimates at $0.25^{\circ}$ resolution over $60^{\circ} \mathrm{S}-60^{\circ} \mathrm{N}$ from 1983 
to the near-present (Ashouri et al. 2015). The precipitation estimation technique combines the PERSIANN algorithm on GridSat-B1 satellite data and an artificial neural network estimation method trained using the National Centers for Environmental Prediction (NCEP) highresolution Doppler radar data. The resulting estimate is adjusted to match the Global Precipitation Climatology Project (GPCP) monthly product version 2.2 (Adler et al. 2003) when regridded to the latter's $2.5^{\circ}$ resolution.

The TRMM 3B42v7 dataset is produced by combining data from the Precipitation Radar (PR) and TRMM Microwave Imager (TMI) instruments aboard the TRMM satellite in an algorithm described in Huffman et al. (2007). Like PERSIANN-CDR, this dataset is also calibrated by monthly gauge data from the Global Precipitation Climatological Center (GPCC) (Rudolf 1993) and the Climate Assessment and Monitoring System (CAMS) monthly rain gauge analysis (Xie et al. 1996). The TRMM mission came to an end on 8 April 2015 and was succeeded by the Global Precipitation Mission (Huffman 2019). TRMM 3B42v7 covers global data within $50^{\circ} \mathrm{N}-50^{\circ} \mathrm{S}$ from 1998 up to near-present, but it is recommended that this product version is used only for January 1998 to September 2014 to ensure homogeneity.

This study used the $0.25^{\circ}$ resolution variant for all the four datasets mentioned. The PAGASA station rainfall dataset was compared with the gridded rainfall datasets at the grid containing or nearest the station location. For analysis involving the monthly and seasonal scales, a month aggregate is discarded for each dataset if there are at least 5 days of missing data within it—removing a total of 19 months distributed across 11 stations. It should be noted that all these datasets have incorporated PAGASA station data in their estimating algorithms at various levels-either as an explicitly listed input in the case of APHRODITEv1101, or as input to the rain gauge-based datasets that were used in calibration or bias correction, in the case of the other three satellite-derived gridded datasets.

\section{d. Comparing climatological rainfall profiles and rainfall event category distributions}

For each climate type, the median monthly and annual totals, as well as the 25 th percentile (P25) and 75th percentile (P75), rainfall values of gridded datasets were first compared with PAGASA to initially identify well and poor performing temporal features of the gridded datasets per climate type. Next, the daily rainfall events were classified into four categories, namely, dry days, light-to-moderate rain days, heavy rain days, and very heavy rain days (Table 1 ). The thresholds of these categories were based on the definition of extreme rainfall indices as recommended by the World Meteorological
TABLE 1. Daily rainfall categories as defined in this study.

\begin{tabular}{lc}
\hline \multicolumn{1}{c}{ Event category } & Rainfall range \\
\hline Dry days & $<1 \mathrm{~mm}$ \\
Light-to-moderate rain days & $1-10 \mathrm{~mm}$ \\
Heavy rain days & $10-20 \mathrm{~mm}$ \\
Very heavy rain days & $>20 \mathrm{~mm}$ \\
\hline
\end{tabular}

Organization (2018). The monthly and multiyear frequency and contribution to the total rainfall of these categories as represented in the gridded datasets were compared with those observed from PAGASA stations.

\section{e. Analyzing the rainfall bias}

The accuracy of the gridded rainfall dataset is quantified by the daily bias $B$, defined as the difference between the gridded dataset value $d$ and the PAGASA value $o$ for each day $i$ [Eq. (1)], and the daily bias fraction (BF), defined as the daily bias divided by the PAGASA value [Eq. (2)]:

$$
\begin{aligned}
B_{i} & =d_{i}-o_{i}, \\
\mathrm{BF}_{i} & =\frac{d_{i}-o_{i}}{o_{i}}=\frac{B_{i}}{o_{i}} .
\end{aligned}
$$

When $\mathrm{BF}=0$, the gridded dataset perfectly replicates the station value; $\mathrm{BF}=0.5$, if the gridded dataset is half of station value; $\mathrm{BF}=1$ if double; $\mathrm{BF}=2$, if triple, and so on. A quantile-quantile $(\mathrm{Q}-\mathrm{Q})$ plot is also drawn to show the deviations in the percentile value distributions of the datasets with respect to PAGASA rainfall, providing an initial survey of the expected bias across all rainfall values. Last, to show the bias of each dataset in more detail, the average monthly bias is also shown with an accompanying split distribution of its contributing daily wet and dry biases.

\section{f. Describing the spatial patterns of bias, correlation, and frequency of extremes}

Seasonal maps comparing each gridded dataset at each PAGASA station location were drawn to determine the reliability of each gridded dataset over the whole Philippines. Aside from showing the seasonal bias value, the bias maps emphasize locations where the biases are consistently observed. The seasonal bias over a location is said to be consistent if a simple majority $(50 \%+1)$ of its constituent monthly biases have the same sign with the seasonal mean bias. Maps of the daily correlation of the gridded datasets with respect to PAGASA were also done over the whole time period to identify areas where rainfall estimates better/poorly fit the observed. Last, maps of the frequencies of dry and very heavy rain events in PAGASA and the gridded 
datasets were compared to identify areas over which the better performing gridded datasets could potentially be used for extremes analyses.

\section{g. Calculating error metrics and skill scores}

The reliability of a gridded dataset's performance in increasingly longer time scales is important for applications that require the use of multiple-scale metrics like climate model evaluation and the development of extremes indices. For this analysis, the daily, monthly and annual rainfall totals of the datasets were compared with PAGASA station values using the root-mean-square error (RMSE), mean absolute error (MAE), linear regression coefficient $\left(R^{2}\right)$, and the Kolmogorov-Smirnov distance (KS), averaged over all stations. These are given by the following expressions:

$$
\begin{aligned}
\mathrm{RMSE} & =\sqrt{\left[\frac{1}{n} \sum_{i=1}^{n}\left(d_{i}-o_{i}\right)^{2}\right]}, \\
\mathrm{MAE} & =\frac{1}{n} \sum_{i=1}^{n}\left|d_{i}-o_{i}\right|, \\
R^{2} & =\left[\sum_{i=1}^{n} \frac{\left(d_{i}-\bar{d}\right)\left(o_{i}-\bar{o}\right)}{(n-1) \sigma_{d} \sigma_{o}}\right]^{2}, \\
\mathrm{KS} & =\max _{k}\left(\left|D_{k}-O_{k}\right|\right),
\end{aligned}
$$

where $d_{i}$ is the gridded dataset value and $o_{i}$ is the PAGASA station value, $\sigma_{d}$ and $\sigma_{o}$ are their respective standard deviations, $D_{k}$ and $O_{k}$ are their cumulative distribution function values at percentile value $k$, and $n$ is the total number of time steps.

The RMSE [Eq. (3)] is the standard deviation of the differences between the station and gridded dataset rainfall. Since this metric squares the difference, large deviations from station values have bigger contributions to the error. The MAE [Eq. (4)] is similar but with all differences taken as absolute values and weighted equally in the score as a simple average. The $R^{2}$ [Eq. (5)] represents the proportion of variance in the station values that is explained by the gridded dataset. Last, KS [Eq. (6)] is a nonparametric measure quantifying the similarity of the rainfall distributions, given as the maximum distance between the cumulative distribution functions of the station and the gridded rainfall.

Furthermore, skill metrics based on a contingency table were used to assess the accuracy of the gridded datasets with respect to station values in the daily time scale. This analysis was performed using four event categories previously described in Table 1 as thresholds. Considering the historical impacts of extremely high rainfall events in the Philippines, the ability of gridded datasets to capture very heavy rainfall is of special interest in this study. Thus, for this analysis, the category for very heavy rainfall days was further divided into three subcategories consistent with those used by Jamandre and Narisma (2013): 1) $20-50 \mathrm{~mm}$, 2) $50-100 \mathrm{~mm}$, and 3) greater than $100 \mathrm{~mm}$.

Daily events that satisfy the category thresholds were aggregated to obtain the number of hits, false alarms, misses, and correct negatives for all years considered. From a roster of skill metrics as documented by WMO (Mason 2016) and regional studies (Zhang et al. 2000; Dinku et al. 2010, 2018), the following were selected: the frequency bias score (FBS), probability of detection (POD), false alarm rate (FAR), and the Peirce skill score (PSS). The formulas are given below, where $A, B$, $C$, and $D$ represent hits, false alarms, misses, and correct negatives, respectively:

$$
\begin{aligned}
\mathrm{FBS} & =\frac{A+B}{A+C}, \\
\mathrm{POD} & =\frac{A}{A+C}, \\
\mathrm{FAR} & =\frac{B}{B+D}, \\
\mathrm{PSS} & =\frac{A}{A+C}-\frac{B}{B+D} .
\end{aligned}
$$

The FBS [Eq. (7)] compares the event detection frequency in the station values with the gridded rainfall estimates, demonstrating underdetection (overdetection) if the value is less (greater) than 1. The POD [Eq. (8)] is the proportion of observed rain events correctly detected by the gridded dataset, which should ideally be close to unity. The FAR [Eq. (9)] compares the false alarms from all detected event instances, with event detection skill becoming indistinguishable from random chance as this value approaches unity. Last, the PSS [Eq. (10)] is the difference between POD and FAR ranging from 0 (no skill) to 1 (perfect skill). Because it measures the overall ability of the dataset to correctly classify events and nonevents, it has shown practical advantages in forecast evaluation compared to the more widely used Heidke skill score, which compares accuracy to random chance (Appleman 1960; Woodcock 1976).

\section{Results}

\section{a. Climatological rainfall profiles}

The spatial patterns of the average seasonal rainfall (1998-2005) from PAGASA stations (Fig. 2) illustrate 
(a) DJF

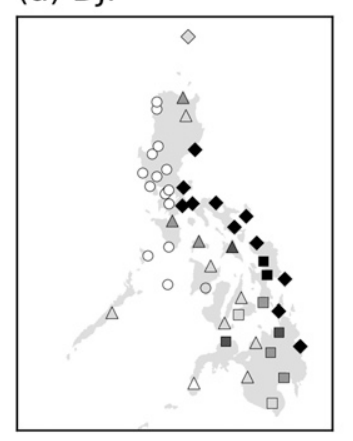

(b) MAM

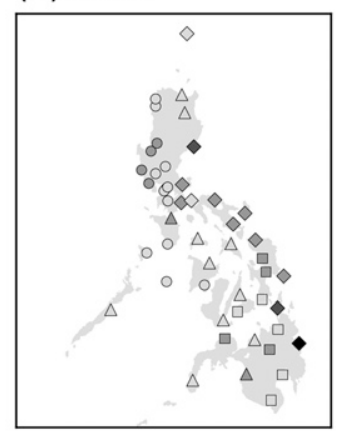

(c) JJA

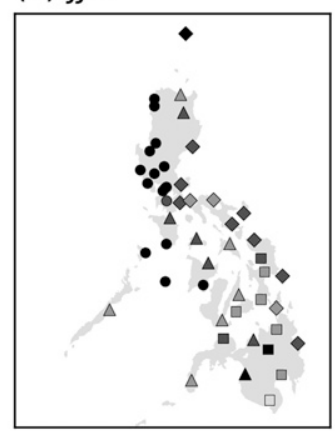

(d) SON

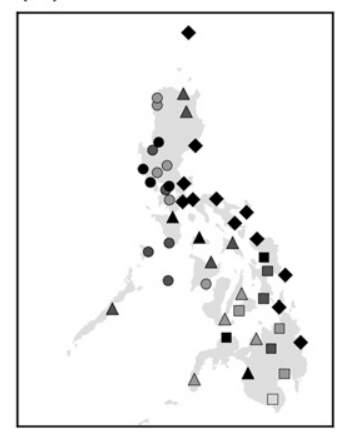

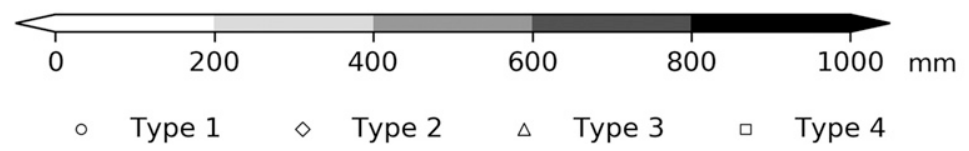

FIG. 2. Average seasonal total rainfall from PAGASA stations for 1998-2005.

the seasonal rainfall description of the climate types of the Philippines. During December-February (DJF) (Fig. 2a), the increased activity of the Asian winter monsoon produces a sharp west-east spatial contrast between the dry $(0-50 \mathrm{~mm})$ Type 1 and wet $(800-1200 \mathrm{~mm})$ Type 2 regions. In contrast, the driest conditions $(0-500 \mathrm{~mm})$ over the whole country follow during March-May (MAM) (Fig. 2b) but with a small rainfall peak over the eastern and western coasts due to easterlies and onset of the summer monsoon, respectively. When the summer monsoon peaks during June-August (JJA), Type 1 regions over the western coast of the Philippines receive the highest rainfall (700-1000 mm). This is considerably lower than the peak in DJF over the eastern coast, but there is high rainfall over a much wider area (Fig. 2c). This rainfall pattern persists during September-November (SON) but with higher rainfall over the Type 2 regions as the winter monsoon and the western Pacific typhoon activity increase (Fig. 2d). Last, stations within Type 3 and Type 4 regions are observed to have relatively low rainfall variation $(300-700 \mathrm{~mm})$ throughout the year.

Although there are large deviations, the monthly profile of all the gridded datasets generally captured the shape of the station profile for every climate type (Fig. 3). Most datasets also showed considerable difficulty in replicating the spread in the monthly values. For Type 1 (Figs. 3a-d), CHIRPSv2 performs best with annual and monthly medians closest to station values, although the rainfall median from June-February is slightly higher than PAGASA median. Meanwhile, TRMM 3B42v7 overestimates the annual median by a similar magnitude as CHIRPSv2, but becomes larger during September-February. On the other hand, APHRODITEv1101 clearly underestimates Type
1 annual rainfall because of the lower summer monsoon peak from May-September. The least accurate profile for Type 1 is from PERSIANN-CDR as it has underestimated the peak on June-September and notably overestimates the median beyond the PAGASA monthly spread.

For Type 2 (Figs. 3e-h), all datasets perform well during the relatively drier months of May-October, but CHIRPSv2 is the only dataset that captures the rainfall peak from September-February, and the spread for all months. The rest of the datasets consistently show difficulty in capturing this peak, which translates to their annual rainfall falling below the annual P25 of PAGASA. TRMM 3B42v7 shows a rainfall median peak close to PAGASA for October-December but largely underestimates the median in January-March. On the other hand, APHRODITEv1101 consistently underestimates the Type 2 profile peak for the entire winter monsoon season from October-February and March-April. Last, PERSIANN-CDR has the poorest performance among the datasets with an annual median deficit because of a very low median during October-April that even falls below or lies close to the P25 of PAGASA.

For intermediate Type 3 (Figs. 3i-1) and Type 4 (Figs. 3m-p), APHRODITEv1101 performs the best among all datasets. Its profile and spread are the closest to PAGASA, albeit slightly underestimated. The other three datasets, in contrast, produce consistent median overestimates for these regions, which are mainly composed of inland valleys and interior islands.

\section{b. Daily rainfall event category distribution}

Among all datasets, TRMM 3B42v7 (Figs. 4e,j) estimated the closest rainfall partitions to PAGASA 

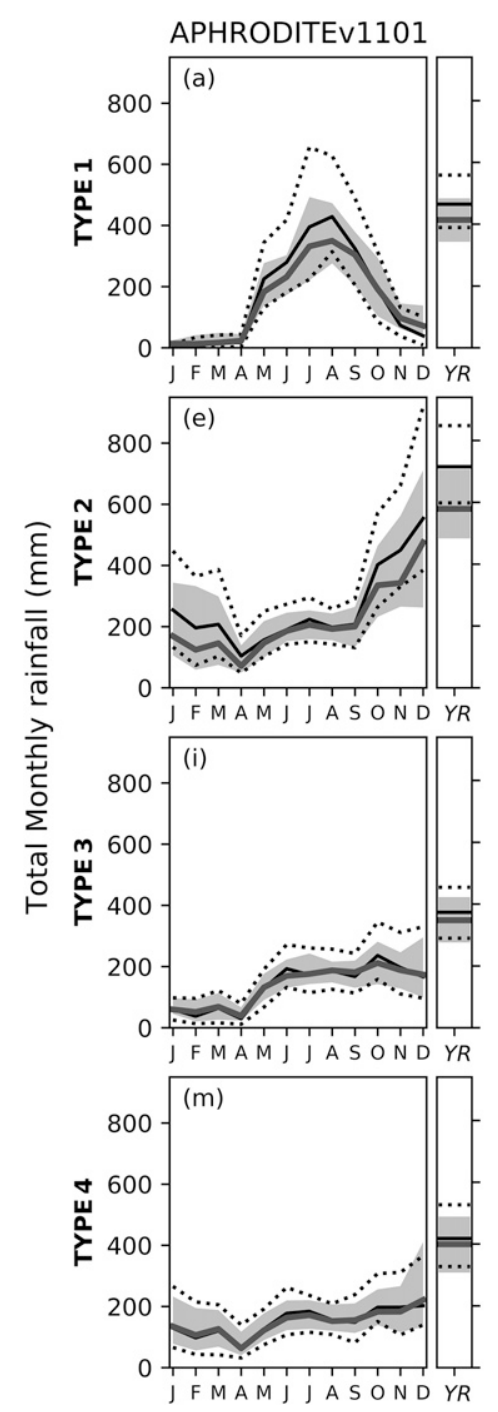
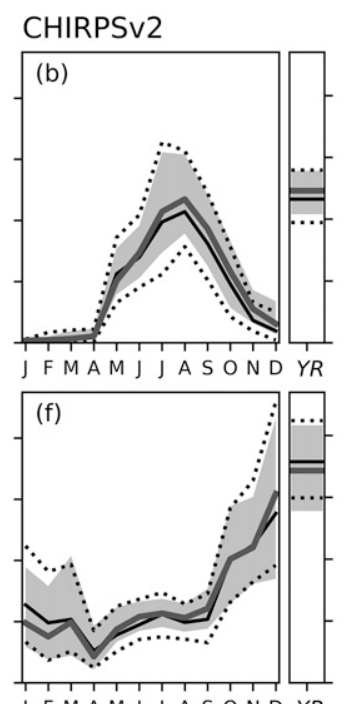

J FMAM J J A SOND YR
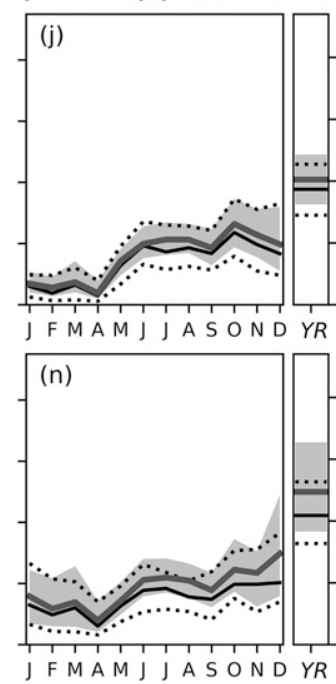

PERSIANN CDR
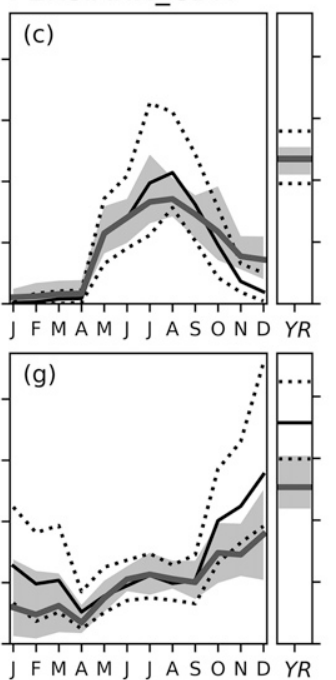

$(\mathrm{k})$
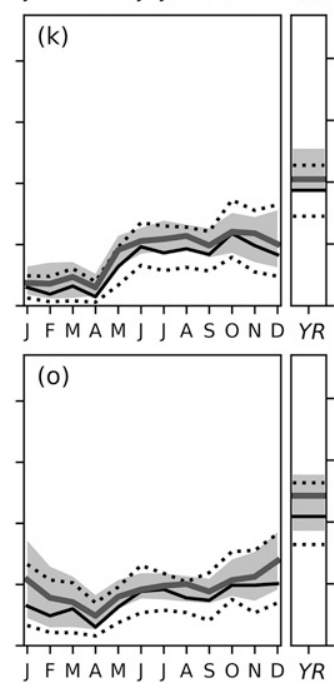

TRMM 3B42v7
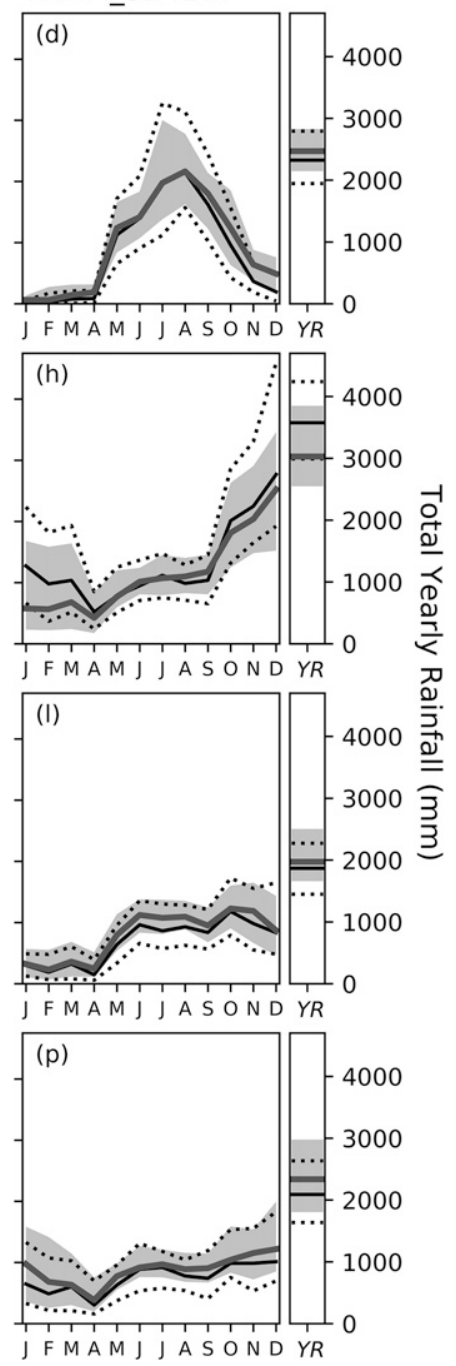

FIG. 3. Monthly and annual rainfall median and spread of PAGASA and the four datasets for each climate type. Solid black lines represent the median total rainfall for PAGASA while the solid gray lines are for each of the datasets. The upper and lower dotted lines represent the PAGASA P75 and P25, respectively, while the gray shadow represents the P25-P75 range of the datasets.

(Figs. 4a,f) in both frequency and contribution. The frequency of dry days is overestimated from November to April and underestimated for the remaining months, but never deviated beyond $5 \%$ of PAGASA. The rainfall contributions of all rainfall categories in TRMM $3 \mathrm{~B} 42 \mathrm{v} 7$ were also accurate to within $5 \%$ of PAGASA for all months, except for very heavy rainfall days, as they are slightly overestimated from November to February by as much as $10 \%$. CHIRPSv 2 also captures the general trend of the frequency and contribution of the station rainfall (Figs. 4c,h), but it exceeds the frequency of rainfall days of PAGASA from June to October by around $3 \%-10 \%$. In terms of contribution, the dataset best captures the station rainfall frequency and contribution from November to February among all datasets, which agrees with its good performance in capturing the peak rainfall profile of Type 2, as discussed in section 3 a.

APHRODITEv1101 and PERSIANN-CDR did not represent the frequency and contribution of rain categories as well as TRMM 3B42v7 and CHIRPSv2. The consistent underestimates in APHRODITEv1101 for Type 1 and Type 2 regions (Figs. 4b,g) could be explained by its evident overrepresentation of light-tomoderate rainfall days for the whole year, which could be as high as double the frequency in June-December and almost triple the observed contribution for MarchMay in PAGASA. Heavy rainfall days also exceed frequencies and contributions in PAGASA by about $40 \%-$ $50 \%$. Among all the datasets, only APHRODITEv1101 was 


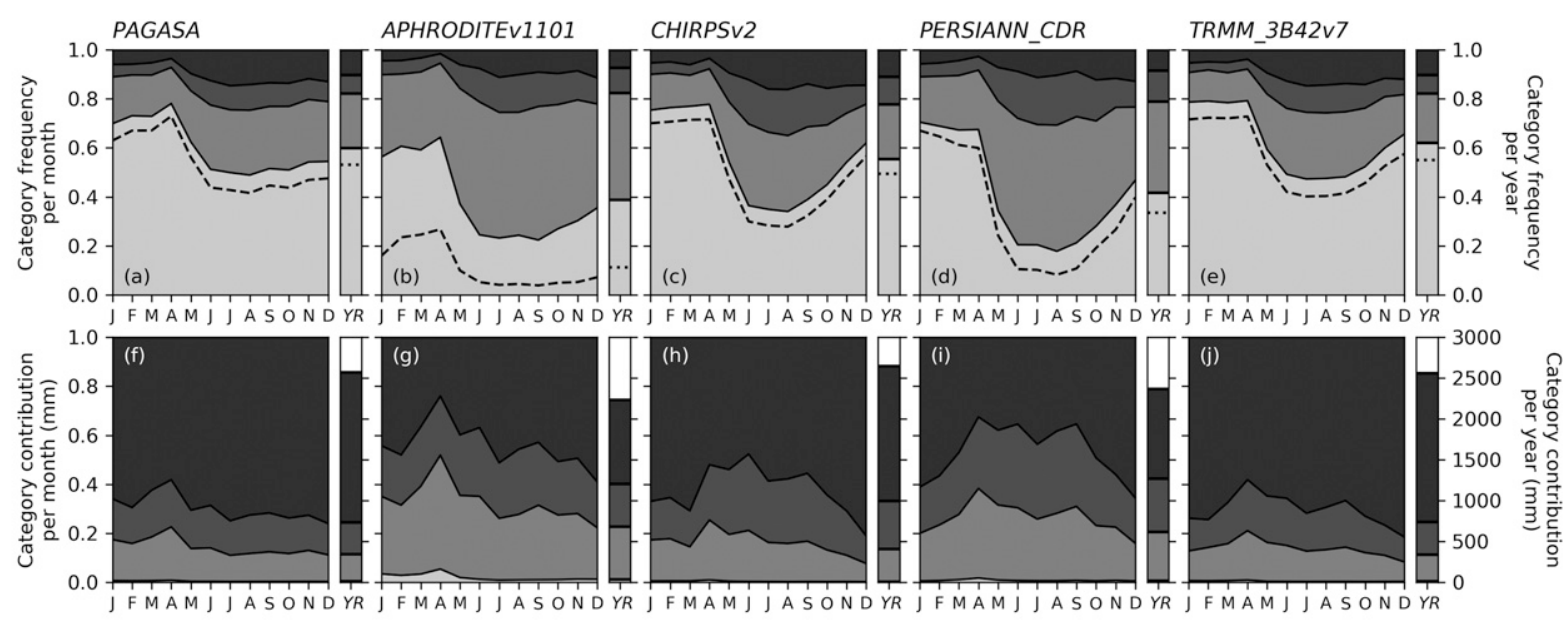

No rain days
$r=0.0 \mathrm{~mm}$$\quad \begin{aligned} & \text { Dry days } \\ & \mathrm{r}<1.0 \mathrm{~mm}\end{aligned} \quad \begin{aligned} & \text { Light to moderate rain days } \\ & \mathrm{r}=[1.0,10.0) \mathrm{mm}\end{aligned}$

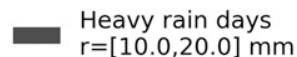

Very heavy rain days
$r>20.0 \mathrm{~mm}$

FIG. 4. Partition plots of the (a)-(e) monthly and annual frequency and (f)-(j) contribution of the four rain event categories recorded in PAGASA and the four datasets over 1998-2005. No rain days $(r=0.0 \mathrm{~mm})$, a subset of dry days, are represented by a dashed line in the frequency plots.

unable to represent the percentage of no-rain days in the dry days. PERSIANN-CDR (Figs. 4d,i) also has a similar excess of light-to-moderate rainfall days but is slightly close to PAGASA. However, PERSIANN-CDR has the highest contribution of heavy rainfall days and the lowest contribution of very heavy rainfall days during March-September for all the datasets, which could be the reason for its low rainfall profile peaks during this period.

\section{c. Rainfall bias}

The excesses and deficits in the frequency and contribution of each daily event category also manifest in the daily rainfall bias and bias fraction (see section 2e), revealing differences between the groundstation-interpolated dataset APHRODITEv1101 and the other three satellite-derived datasets. Large discrepancies in median and spread of bias fractions for dry days and light-to-moderate rainfall days, with respect to PAGASA, indicate that all datasets have difficulty in capturing low rainfall (Fig. 5a). This is expected as rainfall rates less than $2 \mathrm{~mm} \mathrm{~h}^{-1}$ is still below sensitivity thresholds of typical radar-based rainfall measurements (Arulraj and Barros 2017). For dry days, the median bias fractions of APHRODITEv1101, CHIRPSv2, and PERSIANN-CDR at $\mathrm{BF}=6.0,1.5$, and 8.0, respectively, show that the rainfall estimates of the datasets typically exceed twice the observed value. The exception in this category is TRMM $3 \mathrm{~B} 42 \mathrm{v} 7$, which has a negative median bias fraction $(\mathrm{BF}=-1)$, indicating that it estimates dry days more often as a no-rain day. For light-to-moderate rainfall, the performance of all the datasets was seen to improve in terms of the median BF but still retains a wide spread. For heavy and very heavy rainfall days, all datasets underestimate observed rainfall, with reduced bias fraction spreads that is most probably due to fewer events in these categories. Here, APHRODITEv1101 recorded a smaller BF and spread compared to the satellite-derived datasets, but this could be due to its underestimation of the frequency of high rainfall events, as discussed in section $3 b$.

The rainfall Q-Q plot of the datasets (Fig. 5b) shows that APHRODITEv1101 consistently underestimated rainfall across all percentile values by about $80 \%-160 \%$ of PAGASA, which is consistent with its rainfall profile and distribution as discussed in sections $3 a$ and $3 b$. On the other hand, the satellite-derived datasets tend to record higher than PAGASA percentile values up to a threshold specific to the dataset, then underestimate succeeding higher percentiles. TRMM 3B42v7 achieved the closest percentile distribution to PAGASA rainfall, with the widest range of rainfall percentiles (0.6-1.0 and $12.0-100.0 \mathrm{~mm}$ ) within $10 \%$ of PAGASA. Meanwhile, CHIRPSv2 rainfall percentiles fell within $10 \%$ of PAGASA only for the percentiles within $30-50 \mathrm{~mm}$, and PERSIANN-CDR for a much lower range of $8.5-15 \mathrm{~mm}$.

The bidirectional box plots of the rainfall bias (Fig. 6) concisely reveal features of the bias distribution that will not be seen if only the average is presented (see Fig. 7). APHRODITEv1101 has consistently recorded frequent (i.e., $69 \%-77 \%$ of all days) positive daily biases for all months (Fig. 6a). This is expected from the significantly 


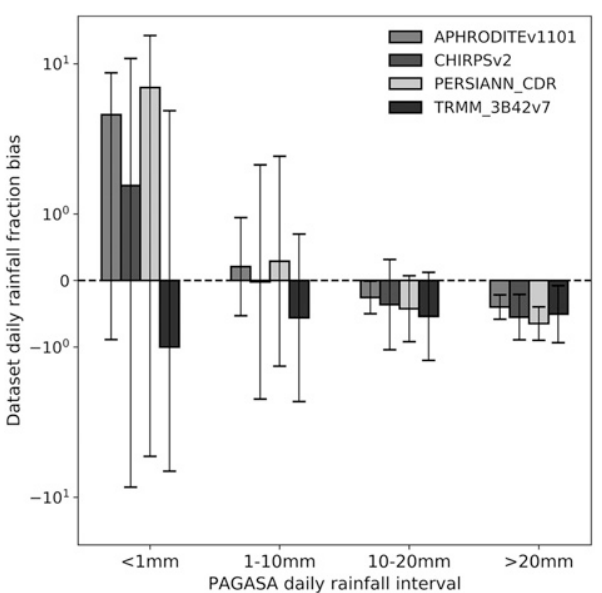

(a)

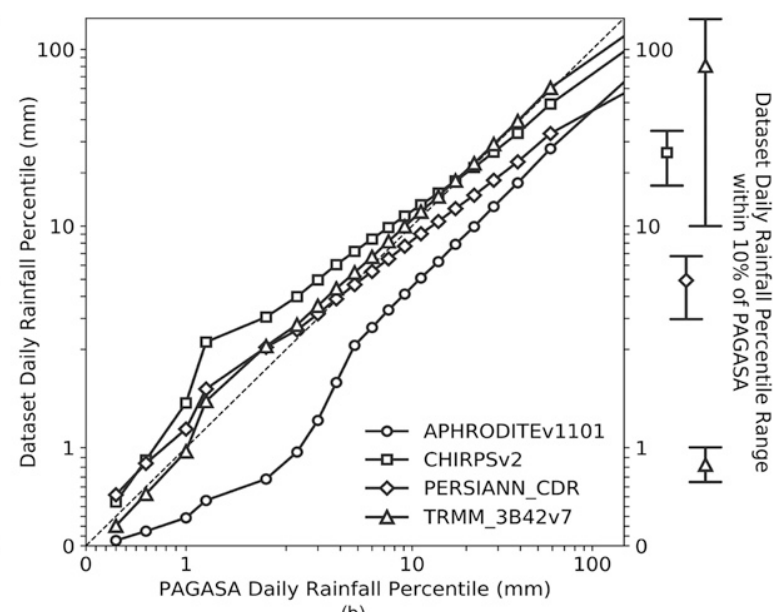

(b)

FIG. 5. (a) Daily rainfall bias distribution of the datasets as fraction of the PAGASA daily rainfall per rain event category. The bars denote the median while the error bars indicate the P25 and P75 fraction bias. (b) Q-Q plot of the four datasets excluding no rain days. Points are calculated with an interval of one percentile. The vertical lines at the right side of the Q-Q plot indicate the range where the rainfall percentile of each dataset fell within $10 \%$ of PAGASA.

larger (smaller) light-to-moderate rain days (dry day) partitions noted previously in section $3 \mathrm{~b}$. However, the monthly median magnitudes of positive biases are remarkably small $\left(0.5-2.0 \mathrm{~mm} \mathrm{day}^{-1}\right)$ compared to the median magnitudes of negative biases $\left(2.6-6.0 \mathrm{~mm} \mathrm{day}^{-1}\right)$, causing an overall average underestimation $\left(5.0-10.0 \mathrm{~mm} \mathrm{day}^{-1}\right)$ of the dataset for all months. This underestimation is consistent with Jamandre and Narisma (2013), and is also observed in other regions, e.g., Pakistan (Ali et al. 2012). It can also be noted that APHRODITEv1101 has the smallest spread of biases among all datasets, which is most likely due to a conservative interpolation algorithm minimizing deviations from the rain gauge values (Yatagai et al. 2012).

With similar partition deficits to APHRODITEv1101 for days with recorded rainfall, PERSIANN-CDR shares the same consistent albeit less frequent positive daily biases for all months $(54 \%-71 \%)$, except in January (Fig. 6c). The monthly median magnitudes for both positive and negative biases are almost twice as large as APHRODITEv1101 for all months. Furthermore, the overall mean negative biases are higher than APHRODITEv1101 with a wider spread. The very high dry bias $\left(10.0-13.0 \mathrm{~mm} \mathrm{day}^{-1}\right)$ during the summer monsoon months from June to September is most prominent for this dataset. This large dry bias is also present in other regions, e.g., Colombia (Dinku et al. 2010) and eastern China (Liu et al. 2015).

CHIRPSv2 (Fig. 6b) and TRMM 3B42v7 (Fig. 6d) are similar in bias distribution, but the former has a slightly larger median daily bias and a wider spread in daily bias for all months. Rainfall is generally underestimated during the summer monsoon months from May to October in both CHIRPSv2 $\left(8.0-10.0 \mathrm{~mm} \mathrm{day}^{-1}\right)$ and TRMM 3B42v7 (1.0-5.0 $\left.\mathrm{mm} \mathrm{day}^{-1}\right)$. During these months, positive daily biases also occur more often $(53 \%-63 \%)$, but the larger spread of less frequent negative biases dominates the overall mean monthly bias for both datasets. For the winter monsoon months of November to February, TRMM 3B42v7 has consistently overestimated rainfall $\left(1.0-3.0 \mathrm{~mm} \mathrm{day}^{-1}\right)$, which is similar to CHIRPSv2 in December and January $\left(1.0-4.0 \mathrm{~mm} \mathrm{day}^{-1}\right)$, but with a slight overestimation in March $\left(1.5 \mathrm{~mm} \mathrm{day}^{-1}\right)$.

Overall, TRMM 3B42v7 performed best in terms of bias because it has the lowest monthly mean biases. This low bias is also seen in other regions such as Brazil (dos Reis et al. 2017), Uganda (Diem et al. 2014), and eastern China (Liu et al. 2015). Interestingly, the positive and negative bias medians for all months are also almost of the same magnitude. Although positive biases occurred slightly more often from April to October, and negative biases for the rest of the year, the difference is at most $9 \%$, which is relatively small compared to the other datasets. This could be expected given its accuracy in reproducing PAGASA event partitions (Fig. 4e,j) and percentile distributions (Fig. 5b).

\section{d. Spatial patterns of bias, correlation, and frequency of extremes}

The signs of the biases of the datasets vary geographically across the Philippines (Fig. 7). In DecemberFebruary (Figs. 7a-d), all datasets show mostly consistent dry biases over eastern Philippines where the winter monsoon rainfall peak is expected. On the other hand, the relatively drier western Luzon and central Mindanao 
(a) APHRODITEV1101

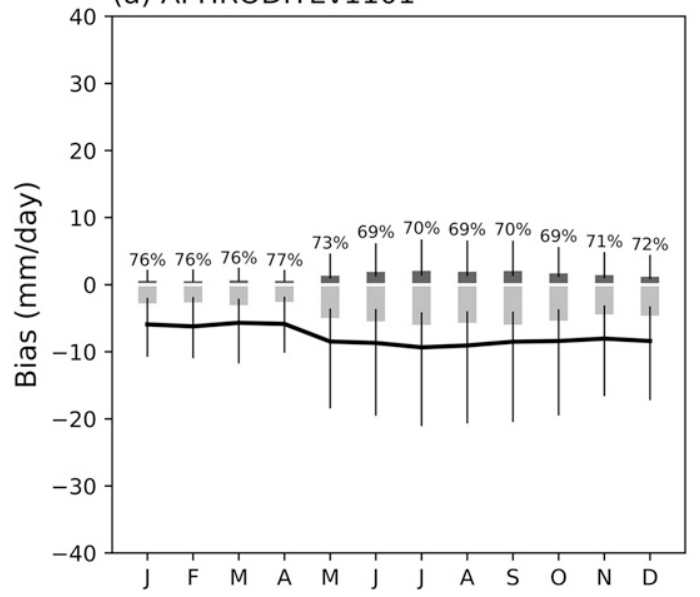

(c) PERSIANN_CDR

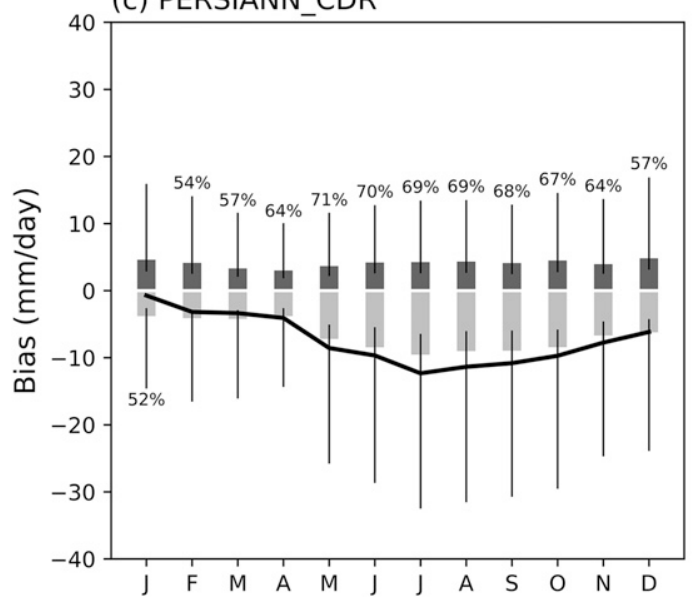

(b) CHIRPSV2

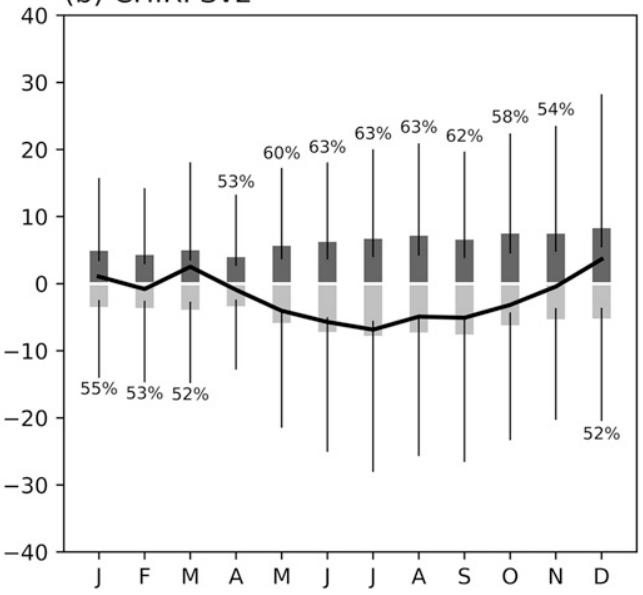

(d) TRMM_3B42v7

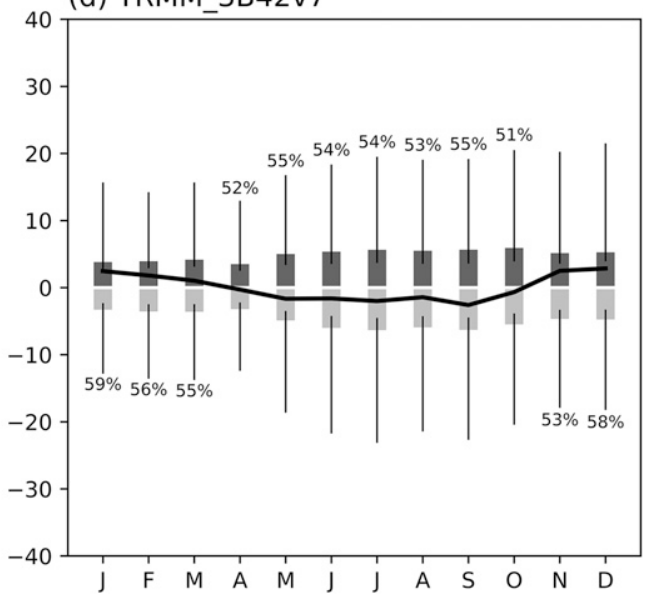

FIG. 6. Bidirectional box plots of the bias of the gridded datasets with respect to PAGASA. The thick black line indicates the monthly mean bias. The dark gray and light gray bars denote the median daily positive and negative bias per month, respectively, while the endpoints of vertical error bars denote the P25 and P75 of each bias sign per month. The percentages located above/below the error bars indicate the bias sign that occurred most frequently for that particular month.

show consistent wet biases at varying magnitudes, most evident for PERSIANN-CDR. During March-May, low biases over the whole Philippines were recorded (Figs. 7e-h), but the monthly signs are mostly inconsistent. APHRODITEv1101 and CHIRPSv2 have the smallest bias magnitudes, while PERSIANN-CDR and TRMM 3B42v7 show some interspersed strong dry and wet biases over some islands. In June-August (Figs. 7i-1), consistent large dry biases were found in the summer monsoon rainfall peak over western Philippines, most noticeable for APHRODITEv1101 (Fig. 7i). The satellitederived datasets (Figs. 7j-1) also have dry biases over western Luzon but show wet biases over the interior islands of western Visayas and northern Mindanao. Finally, for September-November (Figs. $7 \mathrm{~m}-\mathrm{p}$ ), small biases were recorded in central and southern Philippines. However, bias magnitudes varied widely for Luzon: strong, mostly dry biases were seen in APHRODITEv1101 (Fig. 7m), while the rest of the datasets show large biases with a mixture of signs (Figs. $7 n-p$ ).

In terms of the spatial distribution of daily correlation values of the datasets with respect to PAGASA, APHRODITEv1101 (Fig. 8a) recorded the highest values for majority of the locations considered. This could be expected because the dataset uses PAGASA station data in its interpolation method. The highest correlations occur over southwestern Luzon, centraleastern Visayas, and northeastern Mindanao. On the other hand, the satellite-derived datasets show consistent lower correlations with observed values (Figs. 8b-d). For these datasets, correlation over southern Luzon is relatively higher compared to the rest of the country 
APHRODITEv1101
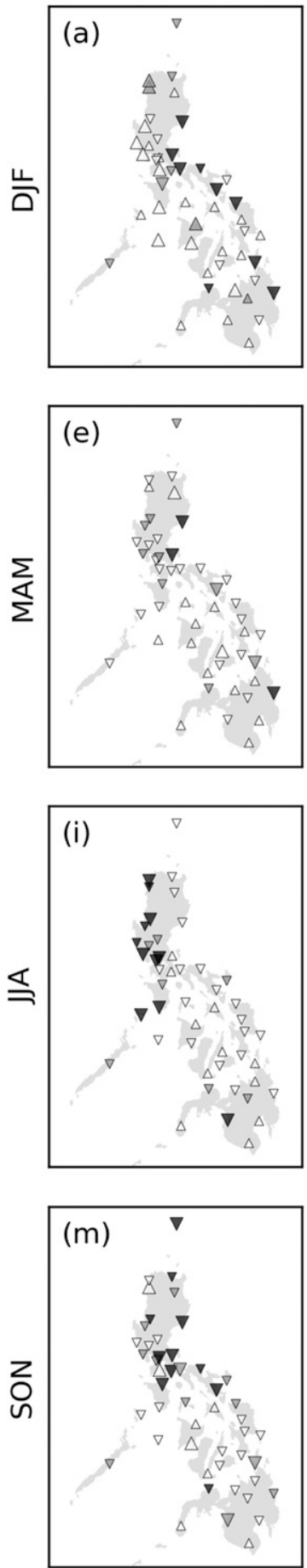

CHIRPSv2

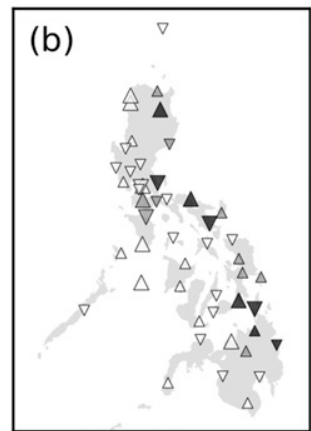

(f)
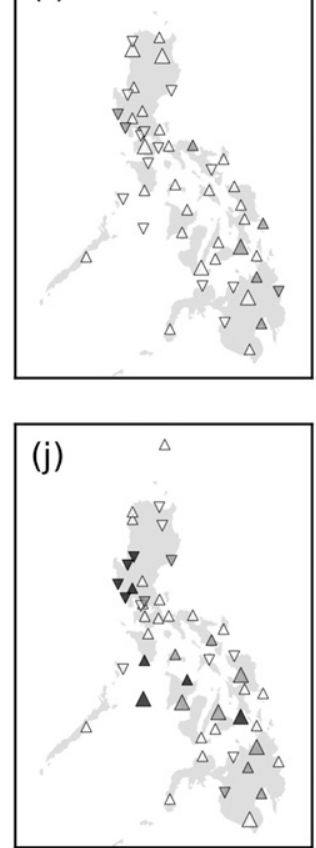

(n)

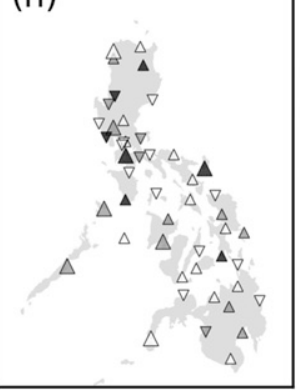

PERSIANN_CDR

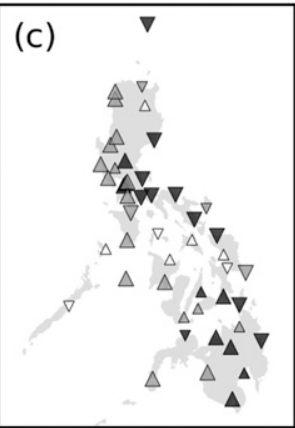

(g)

(o)

2.00
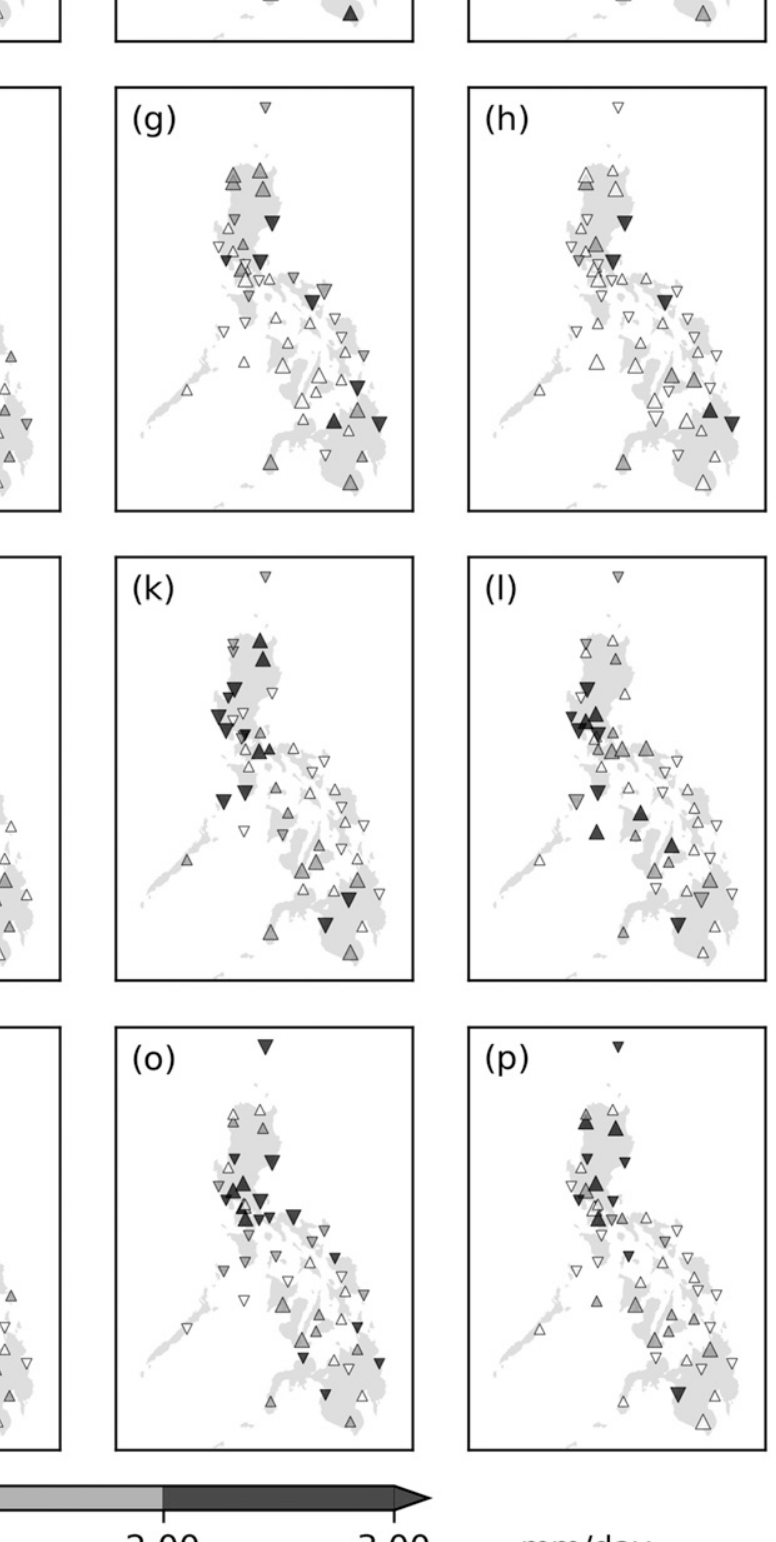

1.00
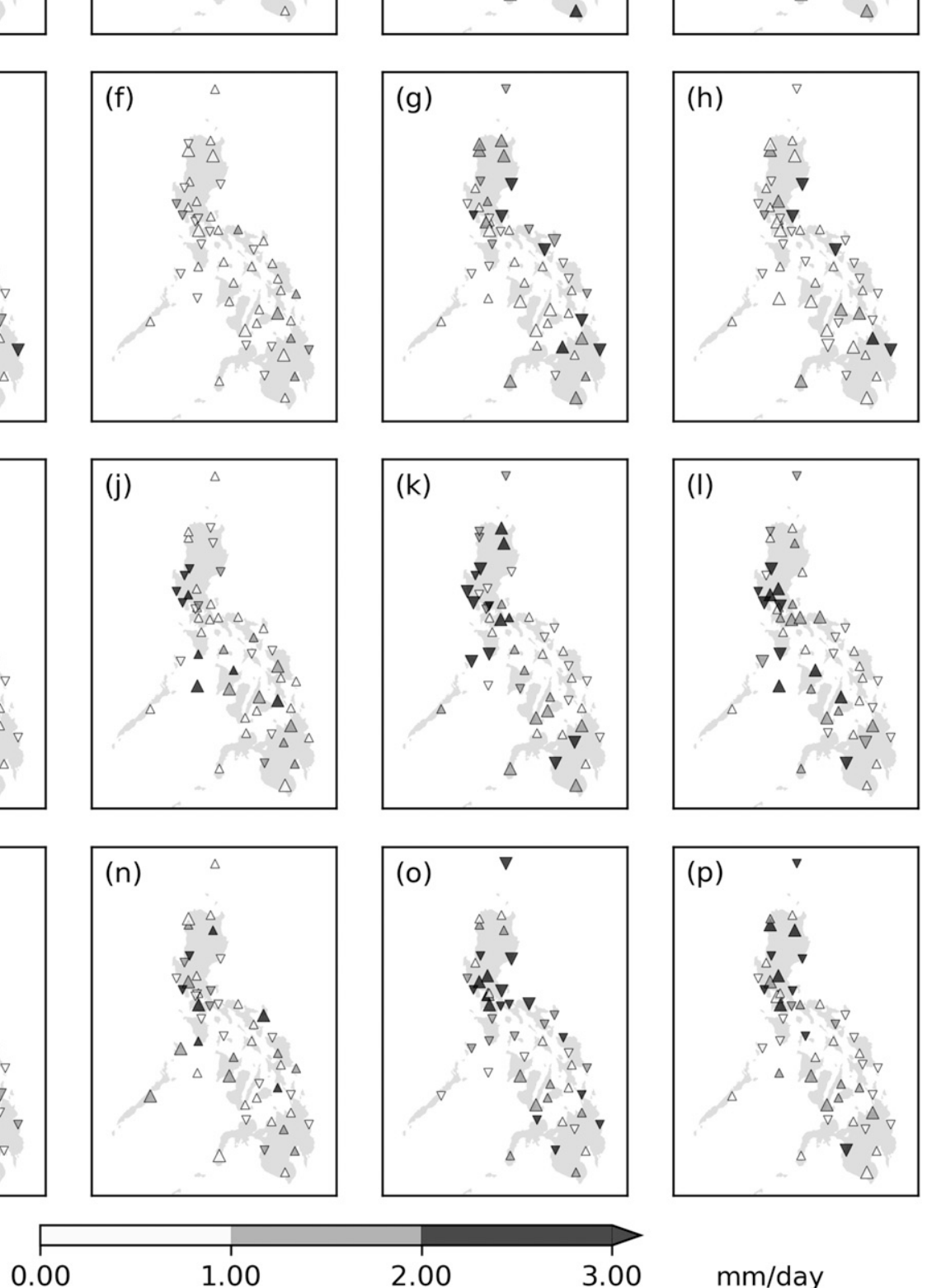

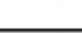

FIG. 7. Seasonal mean daily bias maps of the four datasets with respect to PAGASA for 1998-2005. Stations where wet (dry) bias was recorded is marked by a triangle pointing up (down). Also, stations whose individual monthly bias signs are consistent with the seasonal mean bias sign for more than half of all months within the season are marked with a larger symbol. 


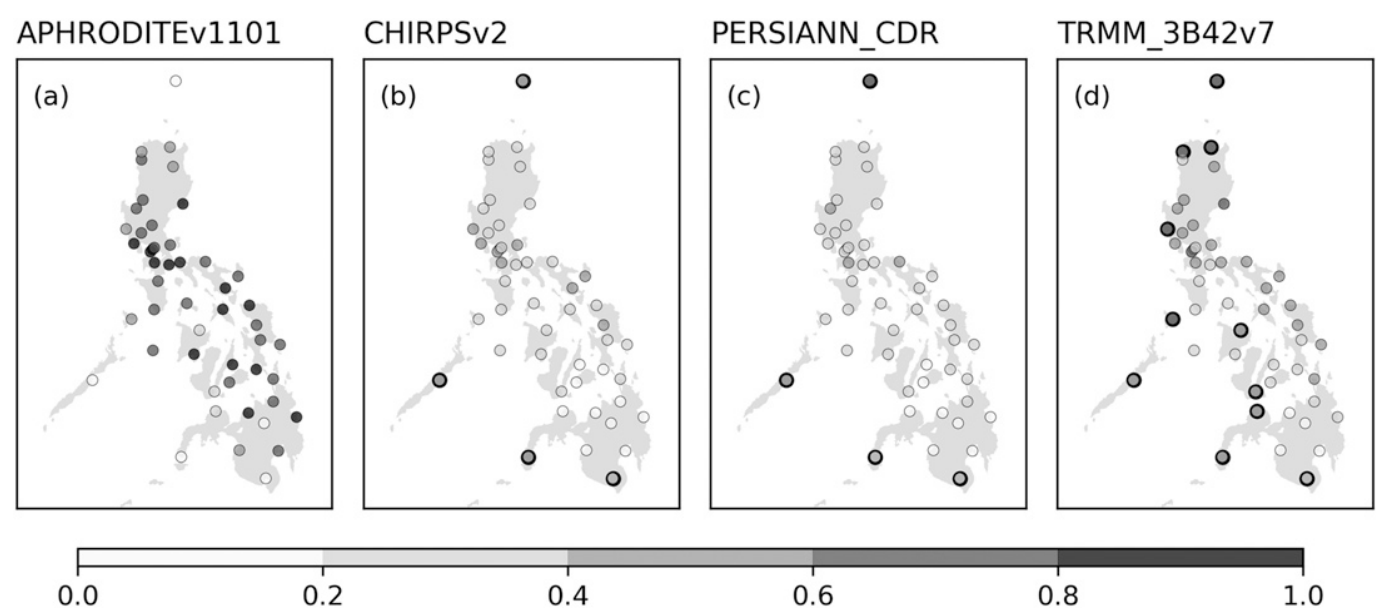

FIG. 8. (a)-(d) Daily correlation map of the four datasets with respect to PAGASA for 1998-2005. Markers with heavier outline in (b)-(d) indicate locations where satellite-derived datasets have higher correlation values than ground-station-interpolated dataset APHRODITEv1101.

while Mindanao has relatively lower values, as was also previously seen in Jamandre and Narisma (2013). Interestingly, all satellite-derived datasets have higher correlation than APHRODITEv1101 over Batanes Islands at the northernmost part of the country, Palawan, and southwestern Mindanao. For TRMM 3B42v7, more locations over western coasts of the country have higher correlation values than APHRODITEv1101, which could be due to the former's better representation of summer monsoon rainfall. Thus, these geographical locations could possibly show the areas where pure interpolation algorithms may not be adequate and where satellite input can help better estimate the observed rainfall.

The capability of these high-resolution datasets to capture rainfall extremes adequately for impact studies, such as drought and torrential rains due to tropical cyclones and monsoon events, is also examined. Both TRMM 3B42v7 (Fig. 9e) and CHIRPSv2 (Fig. 9c) performed well in obtaining the annual spatial distribution of observed PAGASA dry days; thus, these datasets are well suited for use in drought analysis. On the other hand, APHRODITEv1101 (Fig. 9b) and PERSIANNCDR (Fig. 9d) lacked almost half of the observed dry days for the whole country. For the extreme rainfall categories of $20-50,50-100$, and $>100 \mathrm{~mm}$, TRMM 3B42v7 (Figs. 9j,o,t) captured the spatial patterns quite well compared to the other datasets. CHIRPSv2 (Figs. 9h,m,r) slightly overcounted the 20-50 and 50$100 \mathrm{~mm}$ categories over eastern Philippines but was unable to capture the spatial extent of the eastern peak for $>100 \mathrm{~mm}$. In contrast, APHRODITEv1101 (Figs. 9g,l,q) and PERSIANN-CDR (Figs. 9i,n,s) have shown little to no representation of extreme rainfall day counts beyond
$50 \mathrm{~mm}$ for the whole country, with the latter having a slightly better performance for heavy rainfall days.

\section{e. Statistical error metrics and skill scores}

Table 2 shows the RMSE, MAE, $R^{2}$, and KS metrics for the four datasets over the daily, monthly and seasonal time scales. In the daily time scale, high RMSE $\left(>10.00 \mathrm{~mm} \mathrm{day}^{-1}\right)$ and MAE $\left(>4.00 \mathrm{~mm} \mathrm{day}^{-1}\right)$ values were measured for all datasets, with APHRODITEv1101 having the smallest and CHIRPSv2 with the highest values for both. For the monthly and seasonal time scales, the datasets have recorded lower error metrics, which vary from around a tenth to a quarter of the error measured in the daily time scale. For these longer time scales, APRHODITEv1101 still consistently records the lowest MAE; however, TRMM 3B42v7 has the lowest RMSE at monthly and seasonal time scales due to better representation of high rainfall (Figs. 4e,j). On the other hand, the largest daily RMSE and MAE were recorded from CHIRPSv2 in the daily scale, and PERSIANNCDR in the monthly and seasonal scales.

APHRODITEv1101 recorded the highest $R^{2}$ in the daily scale, but this may be due to a conservative approach of reducing residuals by overrepresenting the most frequently occurring dry and light-to-moderate rainfall days (Figs. 4b,g). TRMM 3B42v7 has the next highest $R^{2}$ in the daily scale, and is tied with APHRODITEv1101 in $R^{2}$ for the monthly and seasonal scales. CHIRPSv2 and PERSIANN-CDR have more or less comparable $R^{2}$ for all time scales.

However, despite consistently obtaining high $R^{2}$ for all time scales, APHRODITEv1101 has the poorest KS for the daily time scale. This stems from the dataset's percentile distribution that is shifted toward 

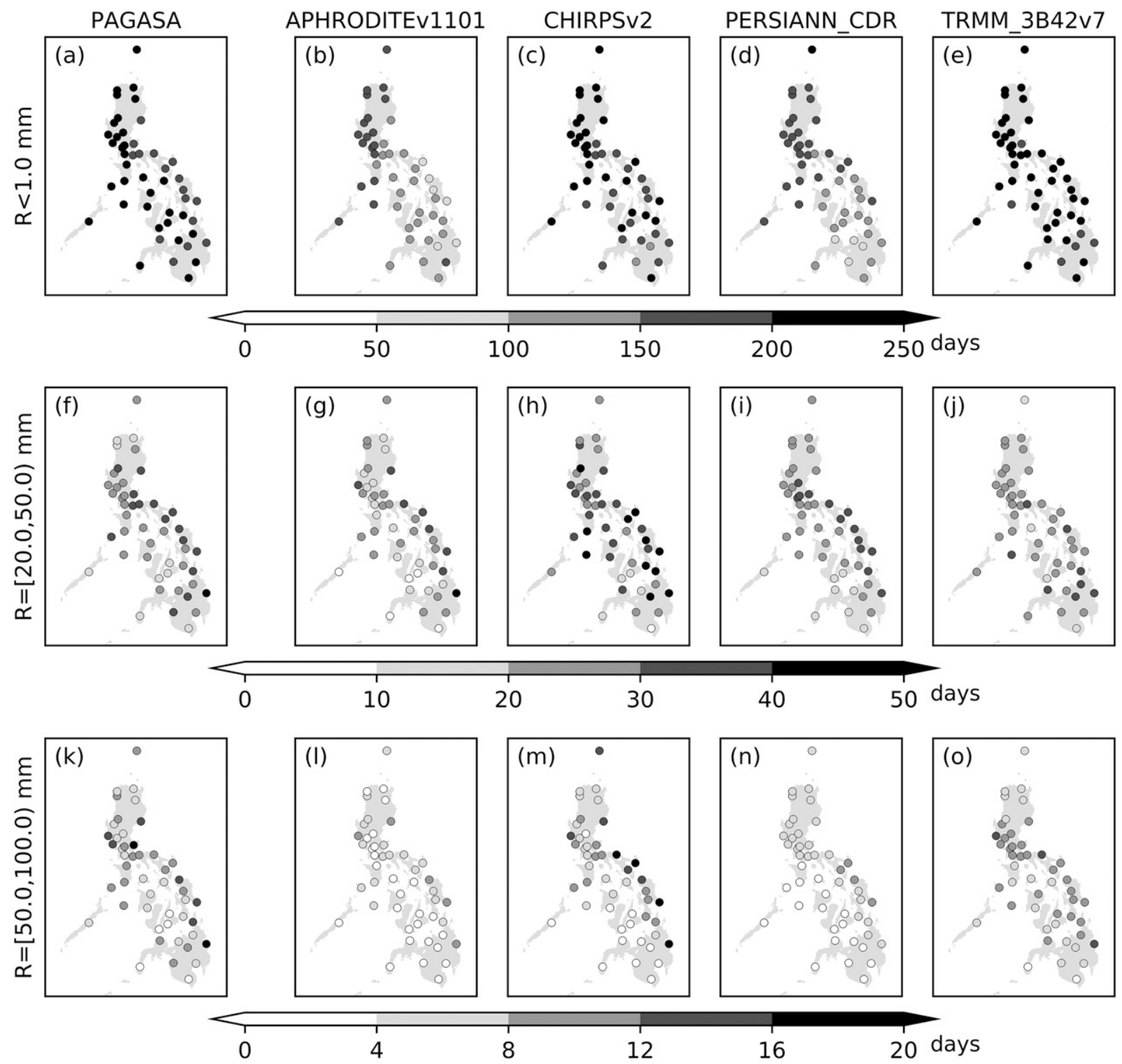

16

20 days
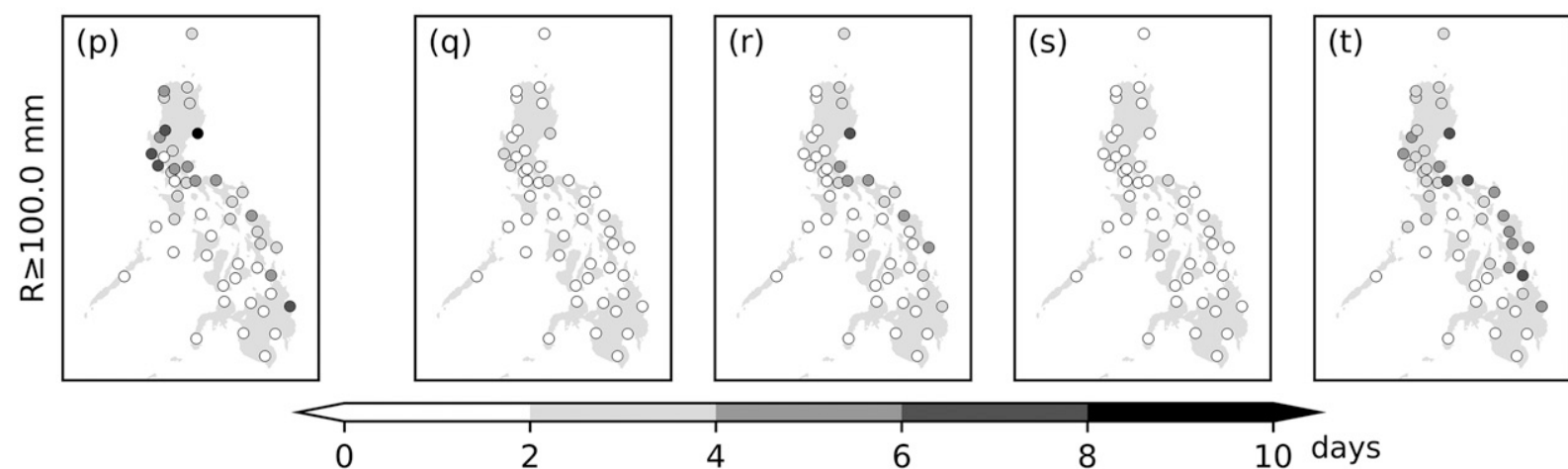

6

8

10 days

FIG. 9. Spatial distribution of the average annual count of each event category of PAGASA and the four datasets for 1998-2005. 
TABLE 2. RMSE, MAE, $R^{2}$, and KS of the gridded rainfall datasets averaged for all stations for the daily, monthly, and seasonal time scales. Values in bold indicate the metric that is closest to ideal among the datasets.

\begin{tabular}{|c|c|c|c|c|c|}
\hline Time scale & Metric & APHRODITEv1101 & CHIRPSv2 & PERSIANN-CDR & TRMM 3B42v7 \\
\hline \multirow[t]{4}{*}{ Day } & RMSE & 11.3 & 16.4 & 15.9 & 15.6 \\
\hline & MAE & 4.5 & 7.4 & 7.2 & 6.6 \\
\hline & $R^{2}$ & 0.6 & 0.3 & 0.3 & 0.4 \\
\hline & KS & 0.4 & 0.1 & 0.2 & 0.1 \\
\hline \multirow[t]{4}{*}{ Month } & RMSE & 3.0 & 3.4 & 4.2 & 2.8 \\
\hline & MAE & 1.9 & 2.3 & 2.9 & 2.0 \\
\hline & $R^{2}$ & 0.8 & 0.7 & 0.7 & 0.8 \\
\hline & $\mathrm{KS}$ & 0.2 & 0.2 & 0.2 & 0.2 \\
\hline \multirow[t]{4}{*}{ Season } & RMSE & 2.1 & 2.1 & 3.0 & 2.0 \\
\hline & MAE & 1.5 & 1.6 & 2.3 & 1.6 \\
\hline & $R^{2}$ & 0.9 & 0.8 & 0.7 & 0.9 \\
\hline & $\mathrm{KS}$ & 0.2 & 0.2 & 0.3 & 0.2 \\
\hline
\end{tabular}

the lower-than-station rainfall values (Fig. 5b). On the other hand, CHIRPSv2 and TRMM 3B42v7 have the best KS in the daily scale because these datasets have more closely reproduced the PAGASA rainfall percentile distribution. Last, in the longer monthly and seasonal time scales, all datasets have more or less the same performance in terms of KS.

The generally meager skill score metrics per daily rain event category for all datasets in the Philippines suggest a strong need for better estimation algorithms and call for added precaution when using these datasets for operational weather forecast verifications (Table 3). As shown by its FBS values, APHRODITEv1101 indicates a tendency to underdetect dry days and largely overdetect light-to-moderate and heavy rain days, which are consistent with its partitioning of these event categories. However, it has garnered the highest POD values among all datasets, correctly detecting more than $75 \%$ to fewer than half of the PAGASA rainfall in the categories from $<1 \mathrm{~mm}$ to $20-50 \mathrm{~mm}$. Although FAR is quite high, APHRODITEv1101 has the lowest false detections among the datasets, especially for dry days. Also, its PSS suggests that APHRODITEv1101 best discriminates categories from dry days to very heavy rainfall days (50-100 mm). However, despite its relatively better skill metrics, this dataset could be specializing in the more frequent low rainfall events and relies on conservative forecasts for rare high rainfall events, again as evidenced by its partition (Figs. 4b,g) and Q-Q plots (Fig. 5b).

The FBS values of PERSIANN-CDR has a similar trend with APHRODITEv1101 but with slightly improved detected events for all except the $>100 \mathrm{~mm}$ category, in which it shows the most propensity to underdetect among all datasets. It has an FBS closest to unity for $20-50 \mathrm{~mm}$ among all datasets, but this category was not represented well in the partition plots (Figs. 4d,i). It has relatively high POD for dry and light to moderate days but poor POD for higher rainfall days with overall high FAR values across all categories. These and the overall low PSS values indicate the limitations of PERSIANN-CDR in estimating daily rainfall over the country.

TRMM 3B42v7 exhibits the smallest detection bias with FBS values closest to unity across most categories with marginally more frequent underdetection (overdetection) in light-to-moderate rainfall (dry) days. The dataset has a strikingly good detection performance in dry days and in very heavy rainfall events above $50 \mathrm{~mm}$ as indicated by high POD values. However, its FAR values are quite high, reaching above $50 \%$ for all event categories, except for dry days. These values reach even up to $80 \%$ for heavy rainfall days, where the POD is also consistently low. It has low PSS for the event categories between 1 and $50 \mathrm{~mm}$, but has high PSS next to APHRODITEv1101 for dry days and $50-100 \mathrm{~mm}$. Furthermore, it recorded more than double the PSS among all datasets for $>100 \mathrm{~mm}$ extreme rainfall events consistent with its performance in capturing event categories of this range (Fig. 9t).

The FBS values for CHIRPSv2 show that it has the least detection bias for light to moderate rainfall for all datasets, a slight underdetection for dry days, and overdetection for heavy rainfall days. It is the only dataset to have FBS $>1.00$ for the $20-50 \mathrm{~mm}$ category, which may well be the reason for its large spread in positive biases (Fig. 6b). Compared to TRMM 3B42v7, CHIRPSv2 has higher POD in the heavy and $20-50 \mathrm{~mm}$ rainfall days but slightly poorer detection for dry days. Its PSS is comparable to TRMM 3B42v7 for all categories, except for a noticeably lower value over the $>100 \mathrm{~mm}$ category.

\section{Conclusions}

The performance of four gridded rainfall datasets with respect to PAGASA station rainfall was evaluated 
TABLE 3. Frequency bias score, POD, FAR, and PSS of the gridded rainfall datasets for the different rainfall event categories. Values in bold indicate the metric that is closest to ideal among the datasets.

\begin{tabular}{|c|c|c|c|c|c|}
\hline Skill metric & Event category & APHRODITEv1101 & CHIRPSv2 & PERSIANN-CDR & TRMM 3B42v7 \\
\hline \multirow[t]{6}{*}{ FBS } & $<1 \mathrm{~mm}$ & 0.65 & 0.91 & 0.69 & 1.02 \\
\hline & $1-10 \mathrm{~mm}$ & 2.01 & 1.01 & 1.69 & 0.91 \\
\hline & $10-20 \mathrm{~mm}$ & 1.37 & 1.51 & 1.70 & 1.03 \\
\hline & $20-50 \mathrm{~mm}$ & 0.82 & 1.19 & 1.00 & 0.98 \\
\hline & $50-100 \mathrm{~mm}$ & 0.48 & 0.86 & 0.50 & 0.95 \\
\hline & $>100 \mathrm{~mm}$ & 0.31 & 0.53 & 0.12 & 1.10 \\
\hline \multirow{6}{*}{ POD } & $<1 \mathrm{~mm}$ & 0.62 & 0.72 & 0.57 & 0.80 \\
\hline & $1-10 \mathrm{~mm}$ & 0.78 & 0.31 & 0.47 & 0.31 \\
\hline & $10-20 \mathrm{~mm}$ & 0.44 & 0.23 & 0.25 & 0.18 \\
\hline & $20-50 \mathrm{~mm}$ & 0.41 & 0.30 & 0.25 & 0.28 \\
\hline & $50-100 \mathrm{~mm}$ & 0.23 & 0.20 & 0.13 & 0.23 \\
\hline & $>100 \mathrm{~mm}$ & 0.27 & 0.17 & 0.04 & 0.46 \\
\hline \multirow[t]{6}{*}{ FAR } & $<1 \mathrm{~mm}$ & 0.05 & 0.21 & 0.18 & 0.21 \\
\hline & $1-10 \mathrm{~mm}$ & 0.61 & 0.69 & 0.72 & 0.66 \\
\hline & $10-20 \mathrm{~mm}$ & 0.68 & 0.85 & 0.85 & 0.82 \\
\hline & $20-50 \mathrm{~mm}$ & 0.50 & 0.75 & 0.75 & 0.71 \\
\hline & $50-100 \mathrm{~mm}$ & 0.52 & 0.76 & 0.75 & 0.75 \\
\hline & $>100 \mathrm{~mm}$ & 0.12 & 0.68 & 0.63 & 0.58 \\
\hline \multirow[t]{6}{*}{ PSS } & $<1 \mathrm{~mm}$ & 0.57 & 0.42 & 0.38 & 0.46 \\
\hline & $1-10 \mathrm{~mm}$ & 0.42 & 0.10 & 0.11 & 0.14 \\
\hline & $10-20 \mathrm{~mm}$ & 0.36 & 0.13 & 0.13 & 0.11 \\
\hline & $20-50 \mathrm{~mm}$ & 0.38 & 0.23 & 0.19 & 0.23 \\
\hline & $50-100 \mathrm{~mm}$ & 0.22 & 0.19 & 0.12 & 0.22 \\
\hline & $>100 \mathrm{~mm}$ & 0.27 & 0.17 & 0.04 & 0.45 \\
\hline
\end{tabular}

using bias analysis, distribution comparisons, and different statistical error metrics and skill scores across different Philippine climate types, event categories, and time scales. Table 4 synthesizes the results through a listing of the potential applications per dataset. APHRODITEv1101 showed an overall propensity to underestimate Philippine rainfall as seen in its consistent dry bias $\left(5.0-10.0 \mathrm{~mm} \mathrm{day}^{-1}\right)$, underestimated season rainfall peak for climate Type 1 and Type 2 and lack of high rainfall days. It recorded the least errors and desirable skill metrics for nonextreme daily rainfall among all datasets, but this could partly be influenced by an overrepresentation of light rainfall. Thus, APHRODITEv1101 is suited for applications that deal with climatological analysis, nonextreme rainfall, and also those geared on long-term trends since it also has the longest time coverage out of the four datasets.

CHIRPSv2 has the best performance in capturing the seasonal peaks of the prominent climate Type 1 and Type 2. It underestimated rainfall for May to October (8.0-10.0 $\mathrm{mm} \mathrm{day}^{-1}$ ) and overestimated for November to February $\left(1.0-4.0 \mathrm{~mm} \mathrm{day}^{-1}\right)$, but the relatively low bias in monthly and seasonal scales is likely due to the large spread of daily biases. It also

TABLE 4. Potential Philippine climate applications of each gridded rainfall dataset.

Seasonal analysis (good seasonal error metrics)

Climatological analysis (captures climate type rainfall

$\checkmark$
profiles)

Rainfall distributions (captures rainfall event partitions and contributions)

Rainfall-based climate indices (good rainfall distribution, good error metrics for all temporal scales)

Drought monitoring (good skill metrics and spatial distribution for rainfall less than $1.0 \mathrm{~mm}$ )

Flood monitoring (good skill metrics and spatial distribution for rainfall greater than $50.0 \mathrm{~mm}$ )

Nonextreme daily rainfall (good skill metrics and spatial distribution for rainfall within $1.0-50.0 \mathrm{~mm}$ ) 
has decent representation of rainfall categories and comparably good performance in terms of the statistical error metrics, which makes it a good dataset for computing rainfall-based climate indices. However, it is most prone to larger errors for light rainfall in the daily scale as it overestimates the frequency of heavy rainfall and fails to capture rainfall beyond $100 \mathrm{~mm}$. Thus, CHIRPSv2 may be best used in studies concerned with seasonal and climatological scales.

Among the four datasets, PERSIANN-CDR is least able to capture aspects of Philippine rainfall and ranks lowest in almost all metrics. The dataset could be used for climatological analysis because it generally captured the rainfall profile of the climate types. However, it showed a wide range of biases with a predominant high dry bias (10.0-13.0 $\left.\mathrm{mm} \mathrm{day}^{-1}\right)$, and poor error metrics in the daily, monthly, and seasonal time scales. Similar deficiencies in the dataset were also observed in studies for other countries (Liu et al. 2015; Dinku et al. 2010)

Last, the satellite-derived TRMM 3B42v7 most accurately replicates the frequency and proportion of rain event categories and best represents the spatiotemporal distribution of both dry and torrential rainfall days, making it useful for studies on rainfall distribution, extremes indices, and flood/drought monitoring. It recorded the lowest bias $\left(1.0-5.0 \mathrm{~mm} \mathrm{day}^{-1}\right)$ and ranks among the highest in terms of statistical metrics in monthly and seasonal time scales. However, it is still subject to high false alarm rates for heavy rainfall and large seasonal biases in certain regions. Nevertheless, this dataset is fit for a wide variety of applications and can be used in investigating climatological and episodic events for the Philippines.

Acknowledgments. This research is supported by the Department of Science and Technology, Philippines through the Students Support Research Fund (SSRF) of the Accelerated S\&T Human Resource Development Program (ASTHRDP) of the Science Education Institute (SEI) and the Philippine Council for Industry, Energy and Emerging Technology Research and Development (PCIEERD), and the Department of Physics, School of Science and Engineering, Ateneo de Manila University.

\section{REFERENCES}

Adler, R. F., and Coauthors, 2003: The version-2 Global Precipitation Climatology Project (GPCP) monthly precipitation analysis (1979-present). J. Hydrometeor., 4, 1147-1167, https://doi.org/10.1175/1525-7541(2003)004<1147: TVGPCP $>2.0 . \mathrm{CO} ; 2$.

Ali, G., Q. U. Zaman, G. Ali, G. Rasul, T. Mahmood, Q. Zaman, and S. B. Cheema, 2012: Validation of APHRODITE precipitation data for humid and sub humid regions of Pakistan. Pakistan J. Meteor., 9, 57-69.
Appleman, H. S., 1960: A fallacy in the use of skill scores. Bull. Amer. Meteor. Soc., 41, 64-67, https://doi.org/10.1175/15200477-41.2.64.

Arulraj, M., and A. P. Barros, 2017: Shallow precipitation detection and classification using multifrequency radar observations and model simulations. J. Atmos. Oceanic Technol., 34, 1963-1983, https://doi.org/10.1175/JTECH-D-17-0060.1.

Ashouri, H., K. Hsu, S. Sorooshian, D. K. Braithwaite, K. R. Knapp, L. D. Cecil, B. R. Nelson, and O. P. Prat, 2015: PERSIANN-CDR: Daily precipitation climate data record from multisatellite observations for hydrological and climate studies. Bull. Amer. Meteor. Soc., 96, 69-83, https://doi.org/10.1175/BAMS-D-13-00068.1.

Bagtasa, G., 2017: Contribution of tropical cyclones to rainfall in the Philippines. J. Climate, 30, 3621-3633, https://doi.org/ 10.1175/JCLI-D-16-0150.1.

Central Intelligence Agency, 2019: East Asia/Southeast Asia: Philippines. World Factbook 2019, accessed 8 November 2019 , https://www.cia.gov/library/publications/the-world-factbook/ geos/rp.html.

Cinco, T. A., R. G. de Guzman, F. D. Hilario, and D. M. Wilson, 2014: Long-term trends and extremes in observed daily precipitation and near surface air temperature in the Philippines for the period 1951-2010. Atmos. Res., 145-146, 12-26, https:// doi.org/10.1016/j.atmosres.2014.03.025.

— ical cyclones in the Philippines. Int. J. Climatol., 36, 4638-4650, https://doi.org/10.1002/joc.4659.

Coronas, J., 1920: The Climate and Weather of the Philippines, 1903 - 1918. Pranava Books, 195 pp.

Corporal-Lodangco, I. L., and L. M. Leslie, 2017: Defining Philippine climate zones using surface and high-resolution satellite data. Procedia Comput. Sci., 114, 324-332, https:// doi.org/10.1016/j.procs.2017.09.068.

Cruz, F. T., G. T. Narisma, M. Q. Villafuerte, K. U. Cheng Chua, and L. M. Olaguera, 2013: A climatological analysis of the southwest monsoon rainfall in the Philippines. Atmos. Res., 122, 609-616, https://doi.org/10.1016/j.atmosres.2012.06.010.

Diem, J. E., J. Hartter, S. J. Ryan, and M. W. Palace, 2014: Validation of satellite rainfall products for western Uganda. J. Hydrometeor., 15, 2030-2038, https://doi.org/10.1175/JHM-D-13-0193.1.

Dinku, T., F. Ruiz, S. J. Connor, and P. Ceccato, 2010: Validation and intercomparison of satellite rainfall estimates over Colombia. J. Appl. Meteor. Climatol., 49, 1004-1014, https://doi.org/10.1175/ 2009JAMC2260.1.

— C. Funk, P. Peterson, R. Maidment, T. Tadesse, H. Gadain, and P. Ceccato, 2018: Validation of the CHIRPS satellite rainfall estimates over eastern Africa. Quart. J. Roy. Meteor. Soc., 144, 292-312, https://doi.org/10.1002/qj.3244.

dos Reis, J., C. Rennó, E. Lopes, J. B. C. Dos Reis, C. D. Rennó, and E. S. S. Lopes, 2017: Validation of satellite rainfall products over a mountainous watershed in a humid subtropical climate region of Brazil. Remote Sens., 9, 1240, https://doi.org/10.3390/rs9121240.

Flores, J., and V. Balagot, 1969: Climate of the Philippines. Climates of Northern and Eastern Asia, H. Arakawa, Ed., World Survey of Climatology, Vol. 8, Elsevier, 159-213.

Funk, C., and Coauthors, 2015a: The climate hazards infrared precipitation with stations-A new environmental record for monitoring extremes. Sci. Data, 2, 150066, https://doi.org/ 10.1038/SDATA.2015.66.

— A. Verdin, J. Michaelsen, P. Peterson, D. Pedreros, and G. Husak, 2015b: A global satellite-assisted precipitation climatology. Earth Syst. Sci. Data, 7, 275-287, https://doi.org/ 10.5194/essd-7-275-2015. 
Hilario, F., R. De Guzman, D. Ortega, P. Hayman, and B. Alexander, 2009: El Niño Southern Oscillation in the Philippines: Impacts, forecasts, and risk management. Philipp. J. Dev., 36, 9-34.

Huffman, G. J., 2019: The Transition in Multi-Satellite Products from TRMM to GPM (TMPA to IMERG). NASA GSFC, 5 pp., https://gpm.nasa.gov/sites/default/files/document_files/ TMPA-to-IMERG_transition_191101.pdf. , and Coauthors, 2007: The TRMM Multisatellite Precipitation Analysis (TMPA): Quasi-global, multiyear, combined-sensor precipitation estimates at fine scales. J. Hydrometeor., 8, 38-55, https://doi.org/10.1175/JHM560.1.

Jamandre, C. A., and G. T. Narisma, 2013: Spatio-temporal validation of satellite-based rainfall estimates in the Philippines. Atmos. Res., 122, 599-608, https://doi.org/10.1016/j.atmosres.2012.06.024.

Joyce, R. J., J. E. Janowiak, P. A. Arkin, P. Xie, R. J. Joyce, J. E. Janowiak, P. A. Arkin, and P. Xie, 2004: CMORPH: A method that produces global precipitation estimates from passive microwave and infrared data at high spatial and temporal resolution. J. Hydrometeor., 5, 487-503, https://doi.org/ 10.1175/1525-7541(2004)005<0487:CAMTPG >2.0.CO;2.

Juneng, L., and F. T. Tangang, 2010: Long-term trends of winter monsoon synoptic circulations over the maritime continent: 1962-2007. Atmos. Sci. Lett., 11, 199-203, https://doi.org/ 10.1002/asl.272.

Kintanar, R., 1984: Climate of the Philippines. PAGASA Rep., $38 \mathrm{pp}$.

Kreft, S., D. Eckstein, L. Junghans, C. Kerestan, and U. Hagen, 2014: Global Climate Risk Index 2015: Who suffers most from extreme weather events?: Weather-related loss events in 2013 and 1994 to 2013. Germanwatch Rep., 32 pp.

Liu, J., Z. Duan, J. Jiang, and A. X. Zhu, 2015: Evaluation of three satellite precipitation products TRMM 3B42, CMORPH, and PERSIANN over a subtropical watershed in China. $A d v$. Meteor., 2015, 151239, https://doi.org/10.1155/2015/151239.

Mason, S. J., 2016: Guidance on verification of operational seasonal climate forecasts. WMO-1220, 79 pp., https://library.wmo.int/ doc_num.php?explnum_id $=4886$.

Murakami, T., and J. Matsumoto, 1994: Summer monsoon over the Asian continent and western North Pacific. J. Meteor. Soc. Japan II, 72, 719-745, https://doi.org/10.2151/jmsj1965.72.5_719.

Prasetia, R., A. R. As-syakur, and T. Osawa, 2013: Validation of TRMM precipitation radar satellite data over Indonesian region. Theor. Appl. Climatol., 112, 575-587, https://doi.org/ 10.1007/s00704-012-0756-1.

Pullen, J., A. L. Gordon, M. Flatau, J. D. Doyle, C. Villanoy, and O. Cabrera, 2015: Multiscale influences on extreme winter rainfall in the Philippines. J. Geophys. Res. Atmos., 120, 32923309, https://doi.org/10.1002/2014JD022645.

Rudolf, B., 1993: Management and analysis of precipitation data on a routine basis. Proc. Int. Symp. on Precipitation and Evaporation, Bratislava, Slovakia, Slovak Hydromet Institute, 69-76.

Usman, M., J. E. Nichol, A. T. Ibrahim, and L. F. Buba, 2018: A spatio-temporal analysis of trends in rainfall from long term satellite rainfall products in the Sudano Sahelian zone of Nigeria. Agric. For. Meteor., 260-261, 273-286, https://doi.org/ 10.1016/j.agrformet.2018.06.016.

Villafuerte, M. Q., J. Matsumoto, I. Akasaka, H. G. Takahashi, H. Kubota, and T. A. Cinco, 2014: Long-term trends and variability of rainfall extremes in the Philippines. Atmos. Res., 137, 1-13, https://doi.org/10.1016/j.atmosres.2013.09.021.

Woodcock, F., 1976: The evaluation of yes/no forecasts for scientific and administrative purposes. Mon. Wea. Rev., 104, 12091214, https://doi.org/10.1175/1520-0493(1976)104\%3C1209: TEOYFF\%3E2.0.CO;2.

World Meteorological Organization, 2018: Guidelines on the definition and monitoring of extreme weather and climate events. WMO Tech Rep., 43 pp., https://www.wmo.int/pages/prog/ wcp/ccl/documents/GUIDELINESONTHEDEFINTIONA NDMONITORINGOFEXTREMEWEATHERANDCLIM ATEEVENTS_09032018.pdf.

Xie, P., B. Rudolf, U. Schneider, and P. A. Arkin, 1996: Gaugebased monthly analysis of global land precipitation from 1971 to 1994. J. Geophys. Res., 101, $19023-19034$, https://doi.org/ 10.1029/96JD01553.

Yatagai, A., K. Kamiguchi, O. Arakawa, A. Hamada, N. Yasutomi, and A. Kitoh, 2012: APHRODITE: Constructing a long-term daily gridded precipitation dataset for Asia based on a dense network of rain gauges. Bull. Amer. Meteor. Soc., 93, 14011415, https://doi.org/10.1175/BAMS-D-11-00122.1.

Zhang, H., T. Casey, H. Zhang, and T. Casey, 2000: Verification of categorical probability forecasts. Wea. Forecasting, 15, 80-89, https://doi.org/10.1175/1520-0434(2000)015<0080:VOCPF> 2.0.CO;2. 